$$
\begin{aligned}
& \text { إز الة الاهون والمواد الصلبة العالقة من مطروحات صناعة الألبان الحاوبة على }
\end{aligned}
$$

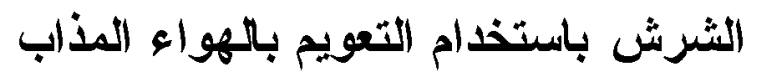

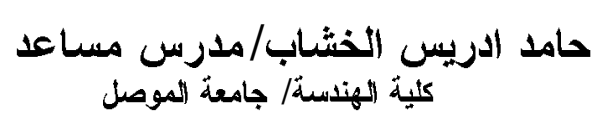

$$
\begin{aligned}
& \text { ساطع محمود الراوي/ استاذ مساعد } \\
& \text { مركز بحوث البيئة/ جامعة الموصل }
\end{aligned}
$$

\begin{abstract}
|المستخنامن

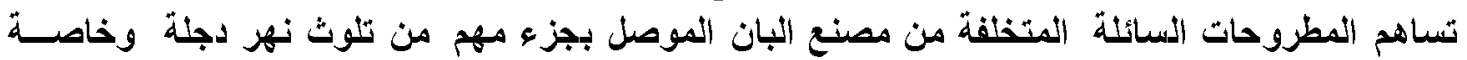

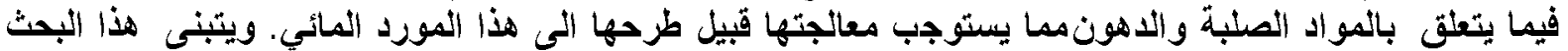

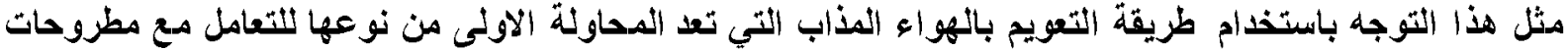

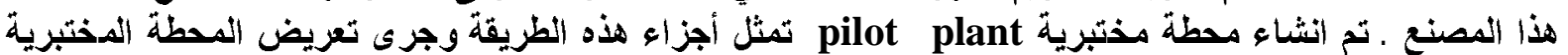

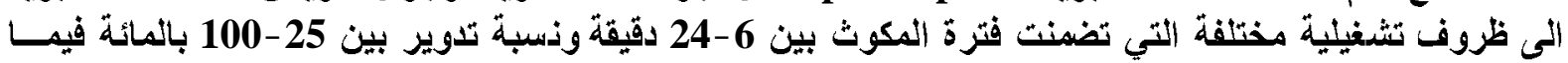

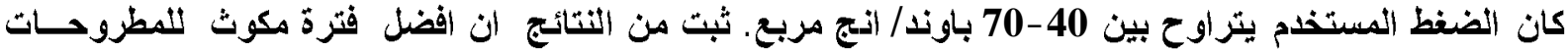

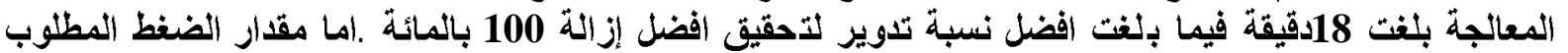

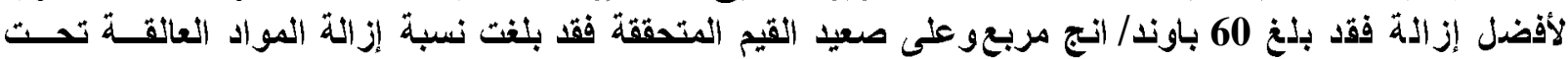

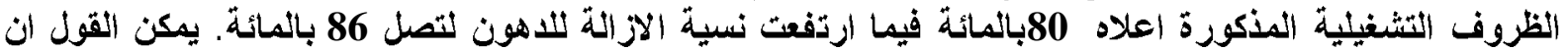

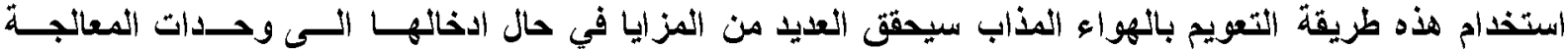

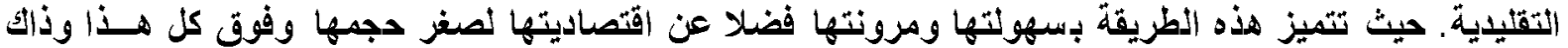
خفض الملوثنات بشكل ملحوظ.
\end{abstract}

\title{
Removal of Oil and Suspended Solids from Dairy Industry by Dissolved Air Flotation
}

\author{
Satee. M. Al-Rawi \\ Assistant Professor \\ Center for Pollution Control
}

\author{
Hamid A. Al-khashab \\ Assistant Lecturer \\ College of Engineering \\ Mosul University
}

\section{ABSTRACT}

Dairy liquid wastes contributes considerably in the pollution of the Tigris within Mosul city particularly when suspended solids and oil pollution are concerned. Dissolved air flotation( DAF) is introduced to tackle the discharges arise from this industry. A pilot plant is constructed for this purpose. The pilot plant is subjected to variety of operating conditions of detention time ( 6-24 minutes), recycle ratio (25-100 \%), pressure (40-70 psi) and air /solids ( $A / S$ ) ratio. The results revealed that the optimum values for detention time, recycle ratio, and pressure were 18 minutes, $100 \%$ and 60 psi respectively. A statistical treatment for the obtained results to relate all the studied factors is made in order to establish the best relation that gives the best results. The percent removal of suspended solids in the dairy discharges amounted to $80 \%$ while that of oil amounted to 86\%. This highly indicates the importance of introducing this physical unit among conventional wastewater treatment units. It is concluded that DAF has many merits represented by ease of operation, considerable reduction of pollutants which may be reflected on subsequent units. Due to short detention time, this unit becomes small and adds to the economy of the treatment. 
ليس من قبيل المغالاة القول بأن الصناعة نعمة ونقمة. فالحضارة و الزرخاء و والرفاه الاجتماعي جميعها مظاهر

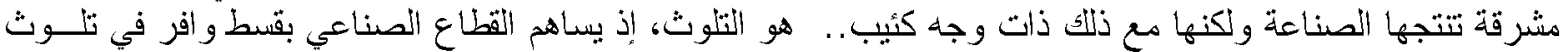

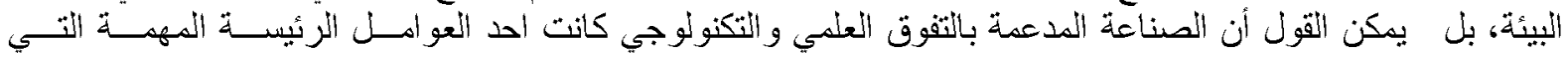

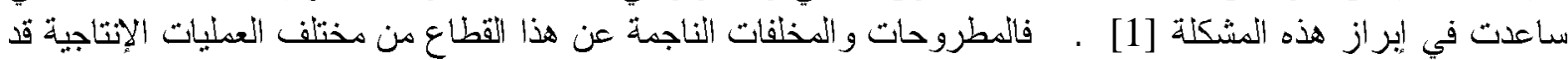

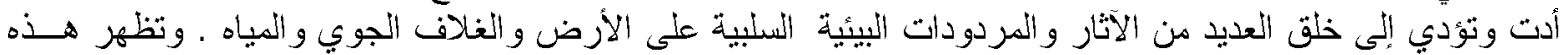

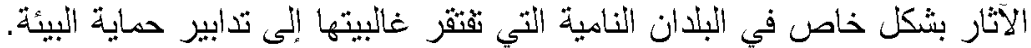

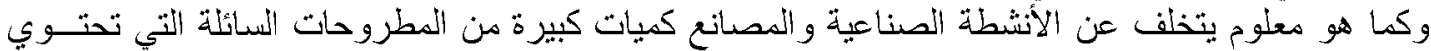

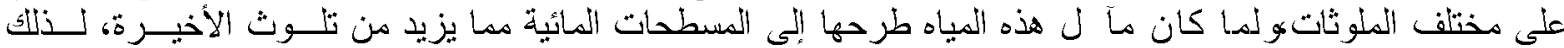

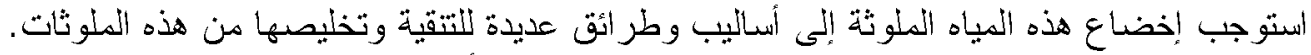

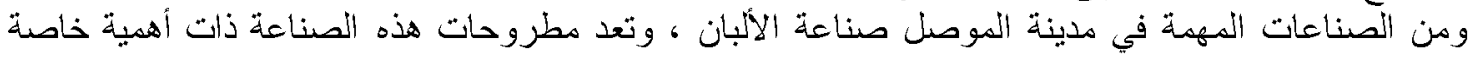

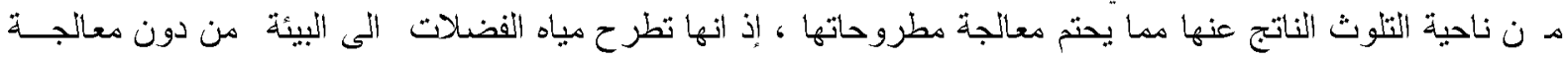

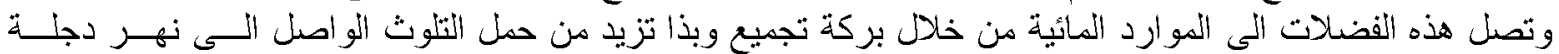

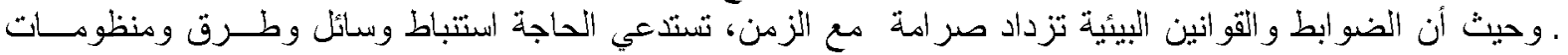

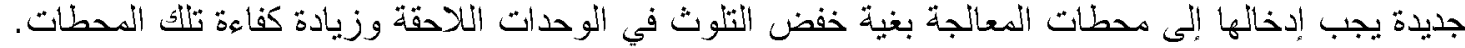

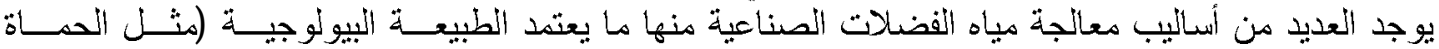

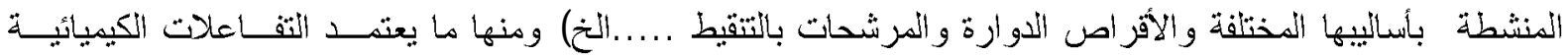

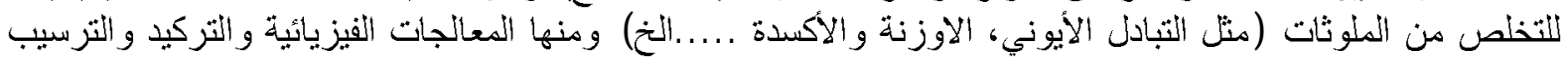

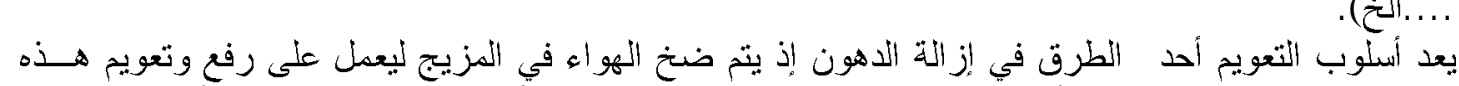

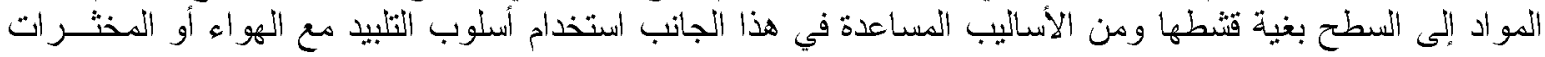

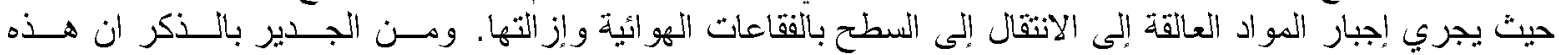

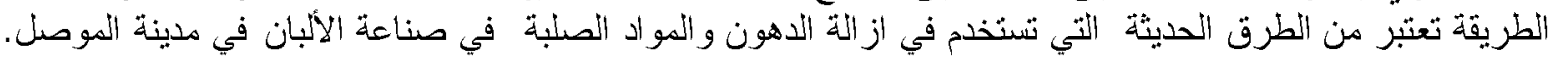

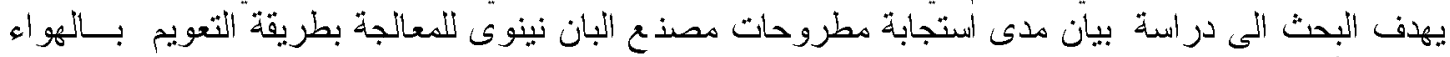

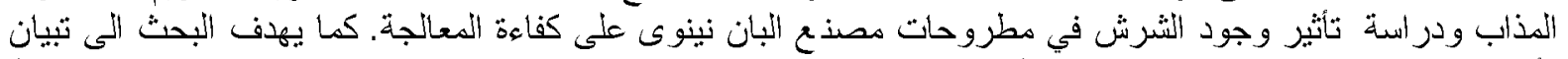

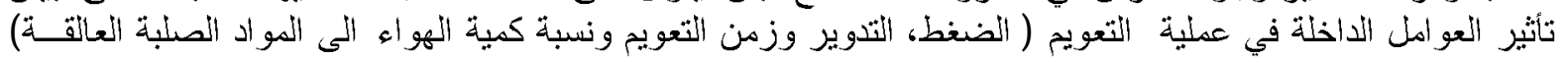
على كفاءة الاز الثة.

الار اسات السابقة

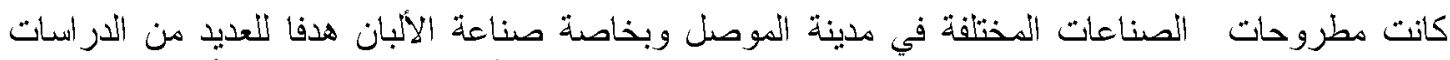

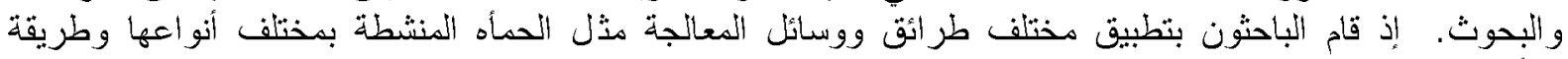

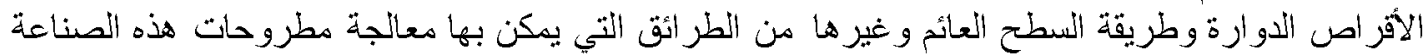

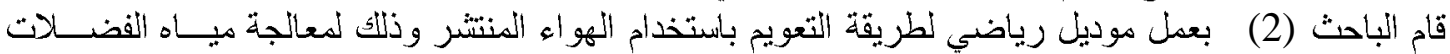

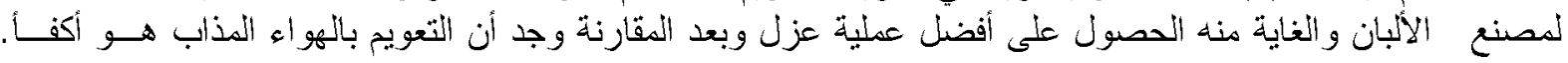

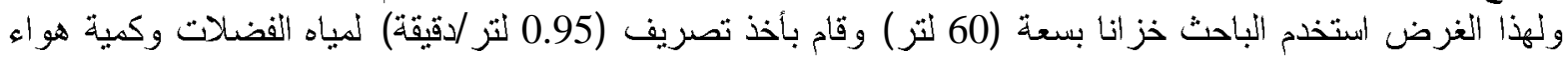

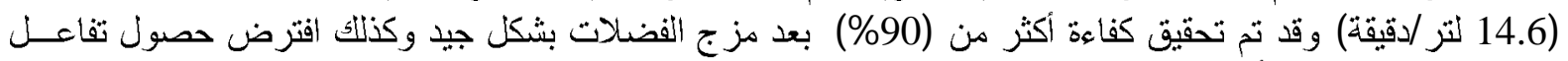

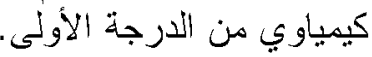

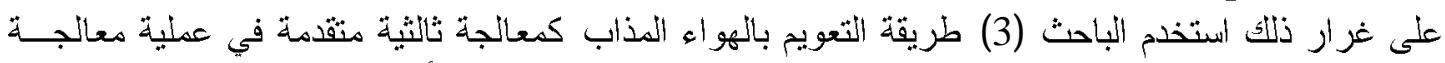

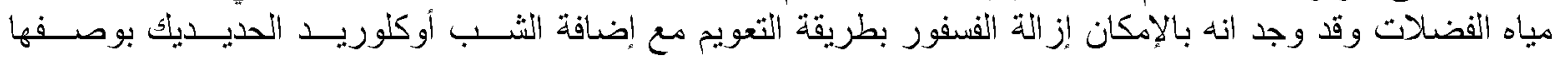

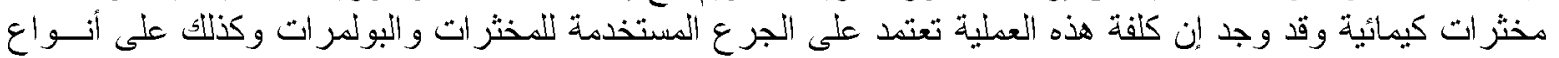

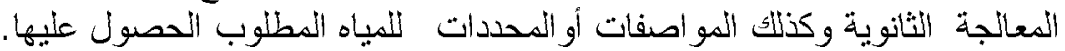

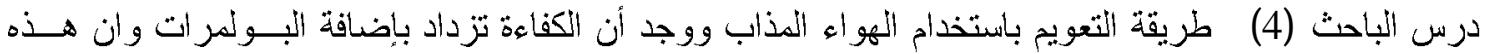

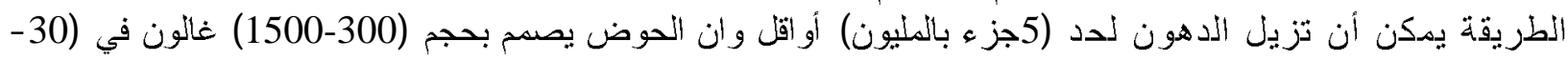

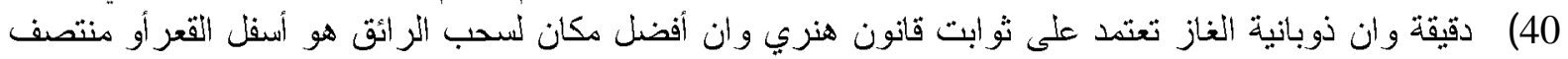

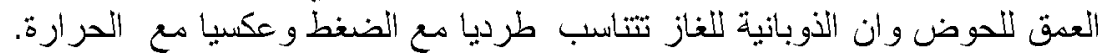

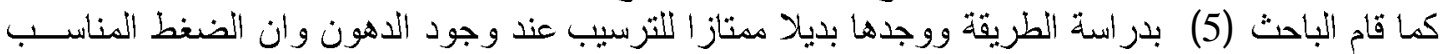

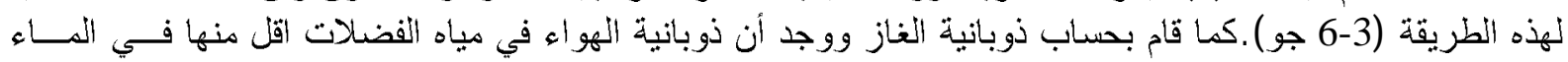


المقطر وان استخدام التذوير لبعض مياه الفضلات يحسن كفاءة الإز اللة بشكل ملحوظ وان نسبة الهو اءه الــى المـــواد

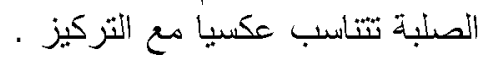

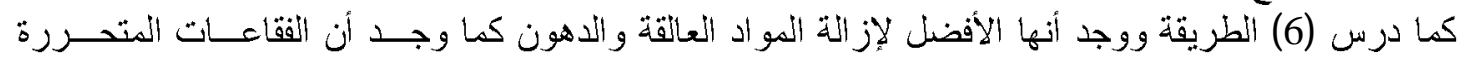

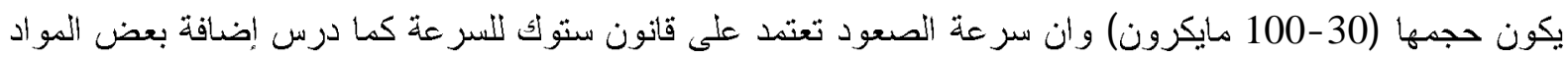
الكيميائية المخثرة و تأثير ها في الإنز الثة فيكان

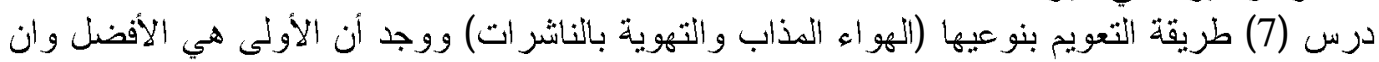

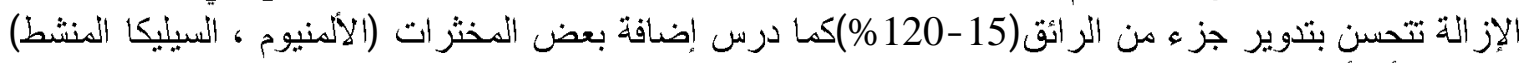

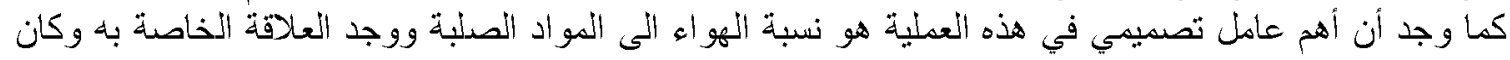

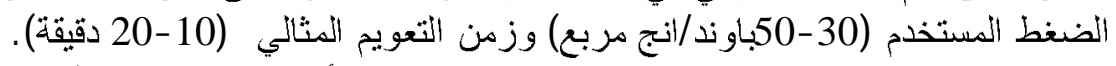

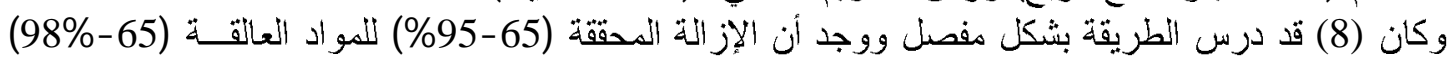

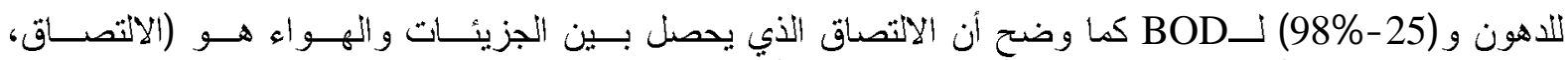

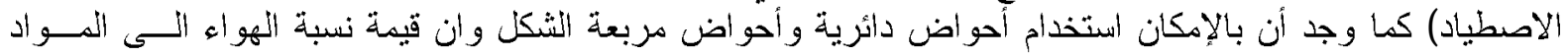

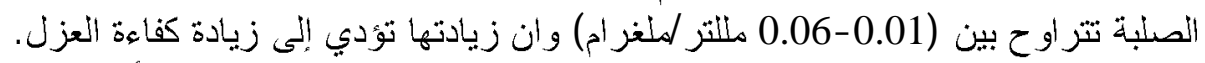

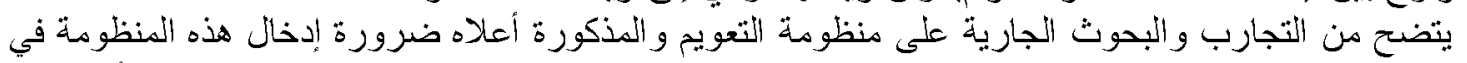

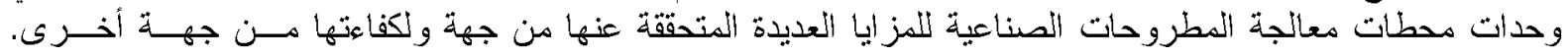

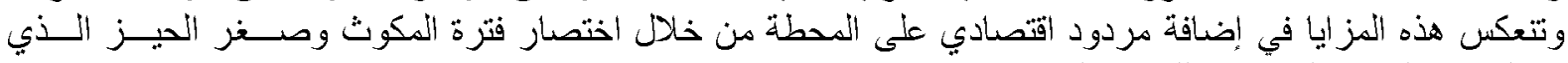

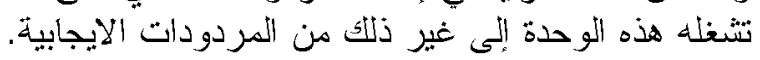

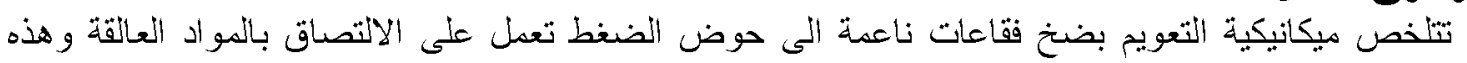

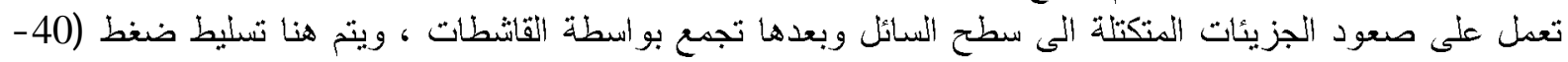

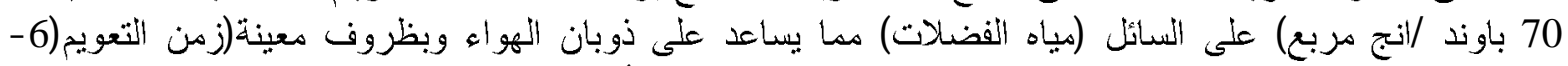

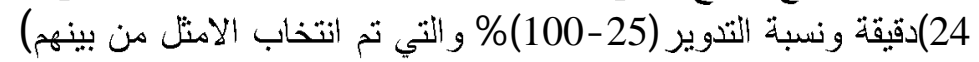

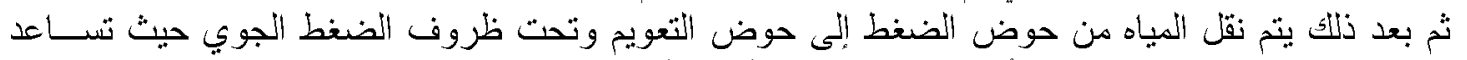

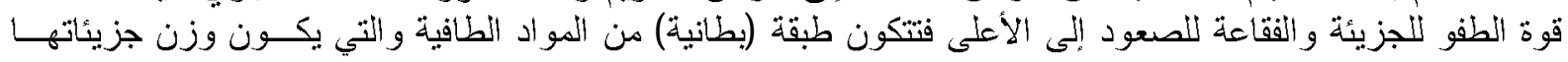

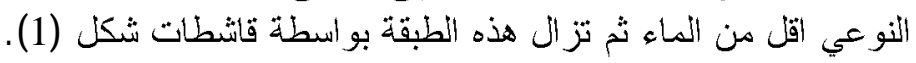

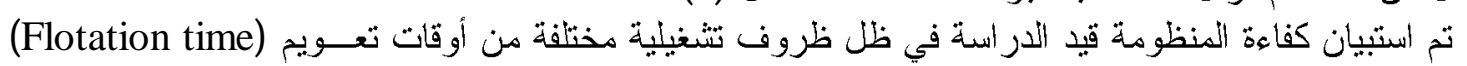

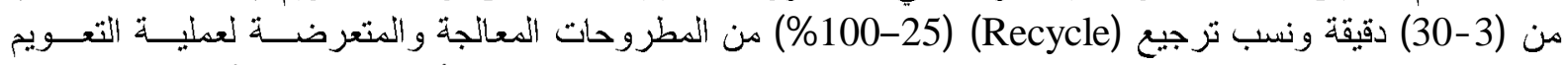

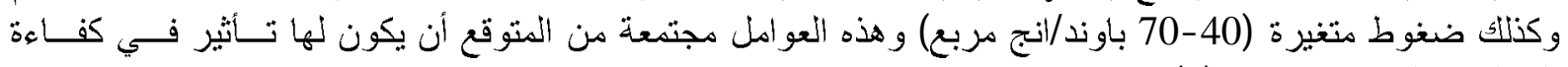

المنظومة المزمع انجاز ها (6) (4)

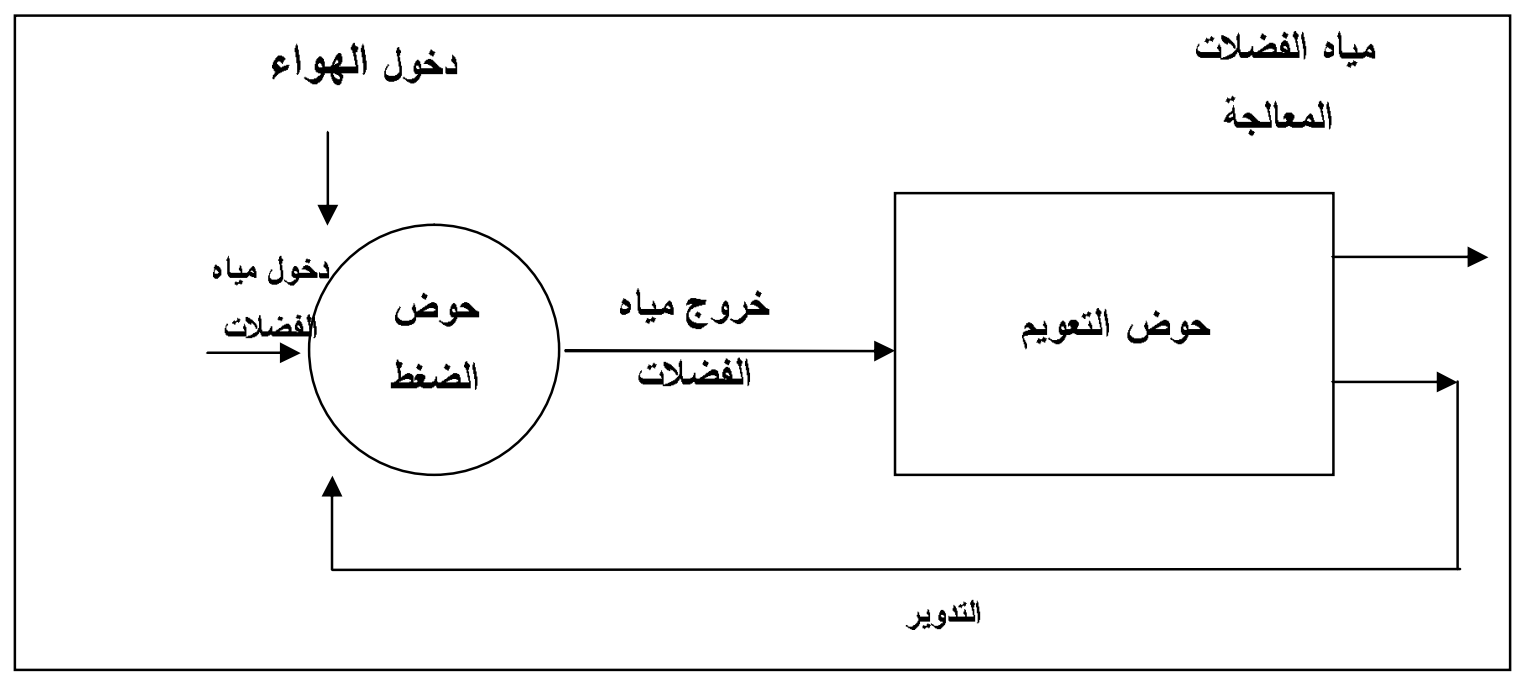

الثكل (1) مخطط يوضح عملية التعويم . 


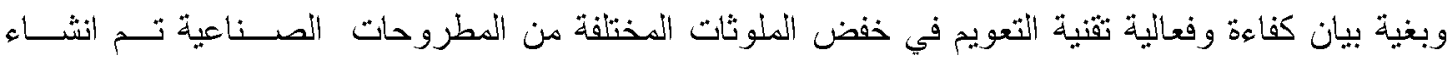
محطة مختبرية (Pilot plant) تتألف من :

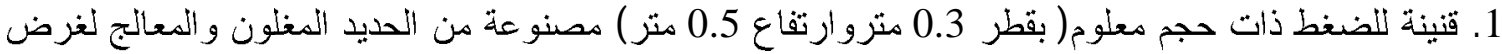

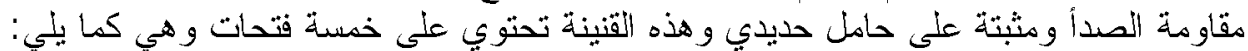

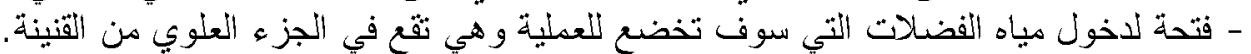

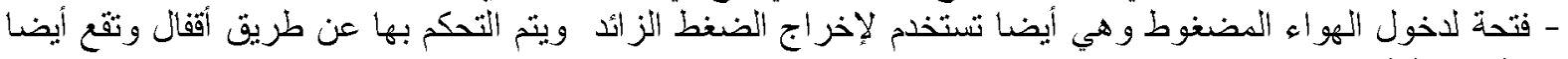

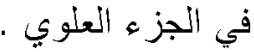
- فتحة يتصل بها مقياس الضغط فئ.

- فتحة تقع في الجزء ألسفلي القنينة يتم من خلالها سحب الماء المشبع إلى دورق التعويم وفيها قفل تحكم (حنفية). - فتحة في القعر للتنظيف

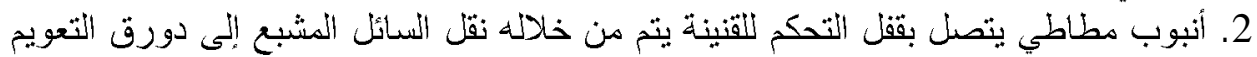

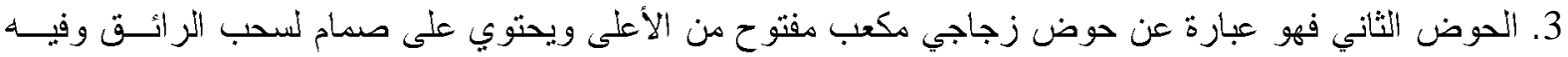
تحدث عملية التطويف 4. ضداغطة هو اء تم استخدام ضداغطة هو أه

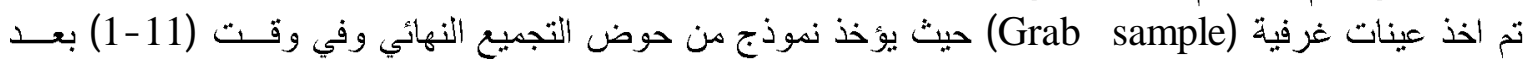

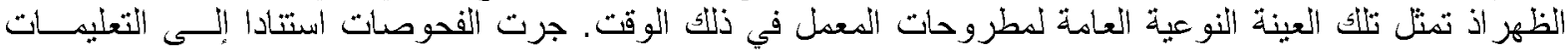
المعتمدة في الطر ائق القياسية(9) وحسب الفقرات الفية المشار إليها في كل فحص وهي في كما يلي:

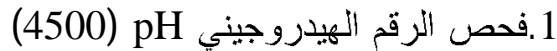

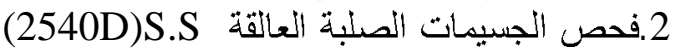
3.فحص المتطلب الكيمياثي للاوكسجين (5220)

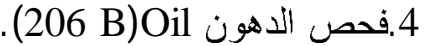

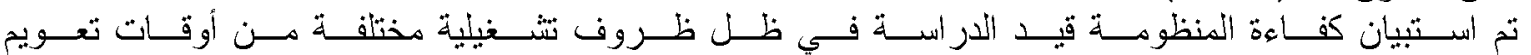
(Flotation time)

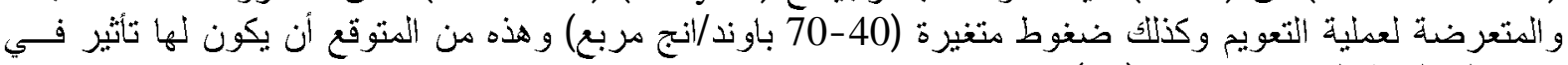

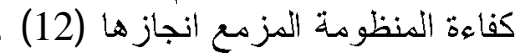
تم تطبيق المعادلات الزياضية لغرض احتساب نسبة الهواء الى وزن المواد الصلبة A/S كالاتي: $\mathrm{A} / \mathrm{S}=\frac{1.3 \mathrm{~s}_{\mathrm{a}}(\mathrm{fp}-1)}{\mathrm{S}_{\mathrm{a}}}$

الجدول (1) قيم ذوبانية الهواءث*

\begin{tabular}{|c|c|c|c|c|}
\hline Temp .C & 0 & 10 & 20 & 30 \\
\hline $\begin{array}{c}\mathbf{S}_{\mathbf{a}}=\mathbf{a i r} \text { Solubility, } \\
\mathbf{m l} / \mathbf{l}\end{array}$ & 29.2 & 22.8 & 18.7 & 15.7 \\
\hline
\end{tabular}

(Metcalf\&Eddy, 2003) ${ }^{*}$

$$
A / S=\frac{1.3 s_{a}(f p-1) R}{S_{a} Q}
$$

اما في حالة استخدام التدوير فتصبح المعادلة بالثكل الاتي: 


\section{النتائج و المناقثة الفرة}

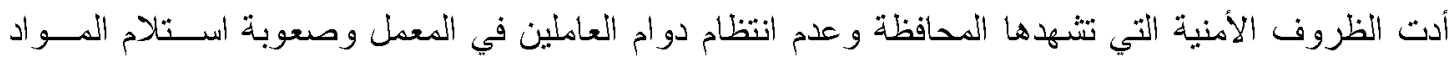

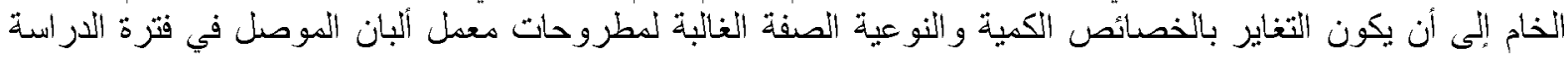

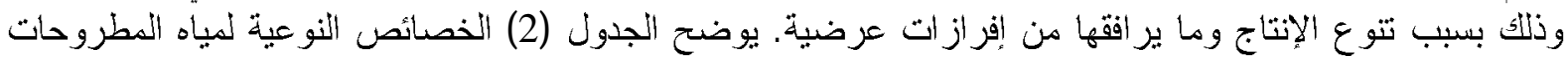

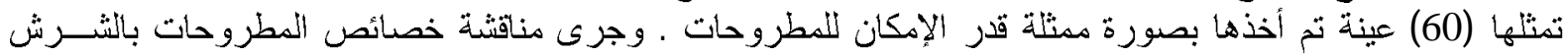
ومدى تأثير التعويم في المعالجة تهنة

الجدول (2): خصائص المطروحات الخام لمعل ألبان نينوى

\begin{tabular}{|c|c|c|c|}
\hline ع شد الأعلى & لحد الأدنى| مـ & 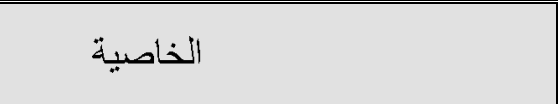 & ت \\
\hline 8.4 & 6.3 & الدانة الحامضية (pH) & 1 \\
\hline 2.4 & 0.6 & الأوكسجين المذاب (ملغرام/لتر) & 2 \\
\hline 8211 & 3191 & المتطلب الكيميائي للأوكسجين (ملغم/لتر) & 3 \\
\hline 1632 & 620 & المو اد الصلبة العالقة (ملغر ام/لتر) & 4 \\
\hline 662 & 182 & الأهون (ملغز ام/لتر ) & 5 \\
\hline
\end{tabular}

واستتادا إلى الجدول أعلاه يمكن وصف مطروحات المعل بأنها قوية حسب الضو ابط المقرة بذلك (13)

و الموضحة في الجدول (2).

الجدول (3): التركية النموذجية لمياه الفضلات المدنية غير المعالجة *

\begin{tabular}{|c|c|c|c|}
\hline \multicolumn{3}{|c|}{ التركيز (ملغر ام/لتز) } & \multirow{2}{*}{ 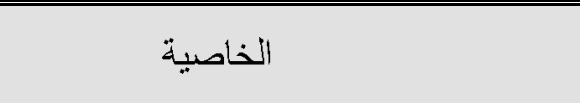 } \\
\hline عيفة التركيز & توسطة التركيز| & قوية التركيز & \\
\hline 120 & 210 & 400 & المو اد الصلبة العالقة (ملغر ام/لتز ) \\
\hline 110 & 190 & 350 & المتطلب الحيوي للأوكسجين (ملغر ام/لتر) \\
\hline 250 & 430 & 800 & المتطلب الكيميائي للأوكسجين (ملغر ام/لتز ) \\
\hline 50 & 90 & 100 & الدهون (ملغز ام/لتزر) \\
\hline
\end{tabular}

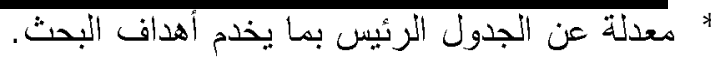

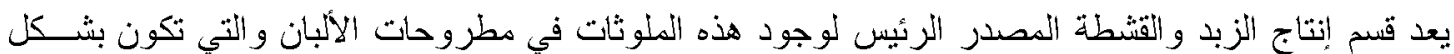

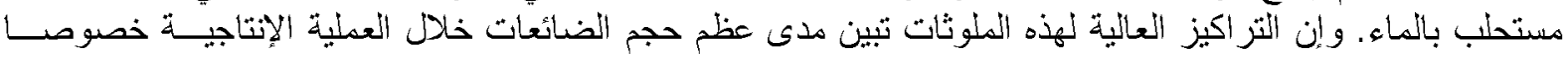

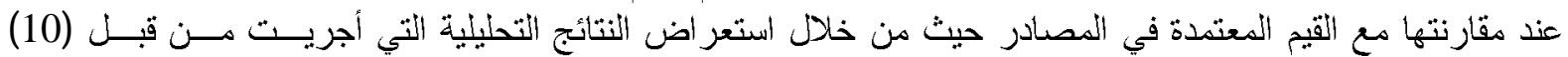

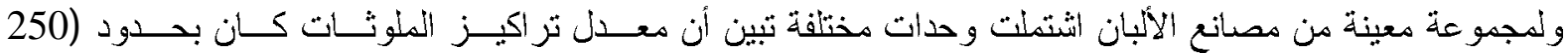

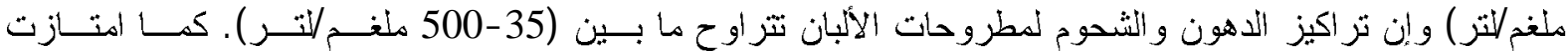

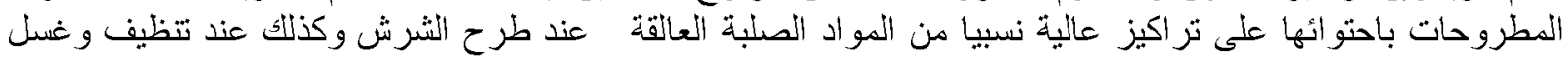

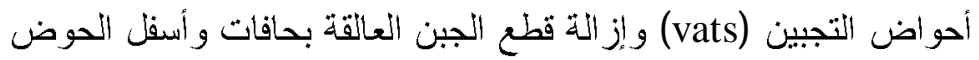

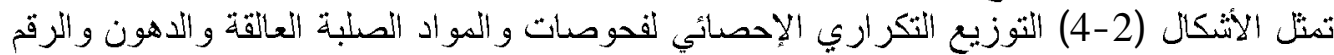

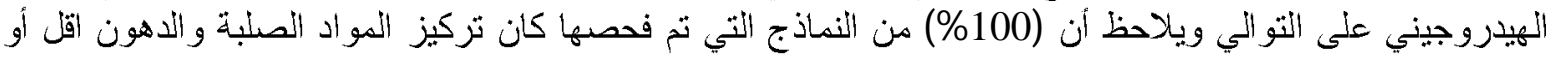

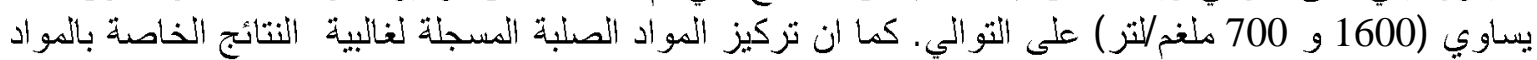

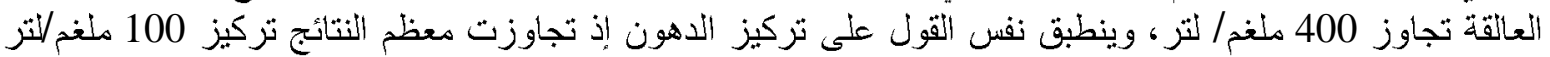

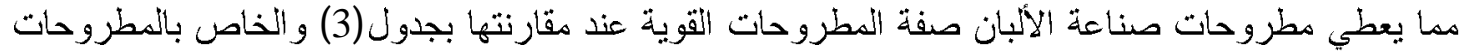

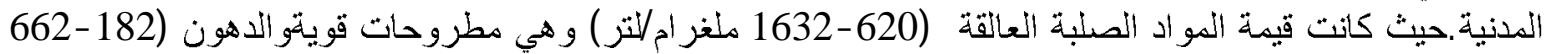

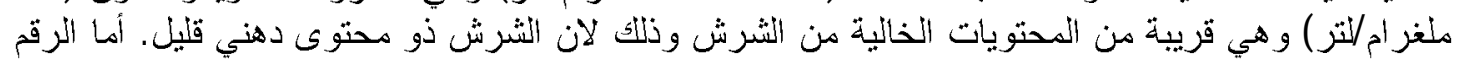

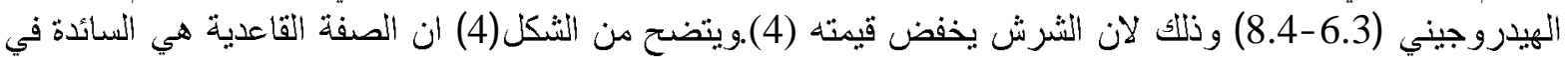

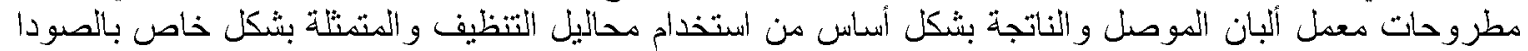
الكاوية (NaOH) وبتركيز (1-2\%)، إن الصفة القاعدية لمطروحات مععل الألبان تكون مؤثرة في منع تكوين غاز 
$\begin{array}{llll}\text { Al-Rafidain Engineering } & \text { Vol.19 } & \text { No.1 } & \text { February } 2011\end{array}$

و إذابة الدهون لتصبح بشكل مستحلب (Emulsion Oil) وكذلك تنظيم قيم (pH) ضمن مدى بتر اوح بين

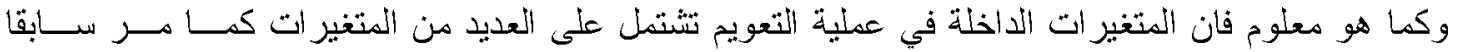

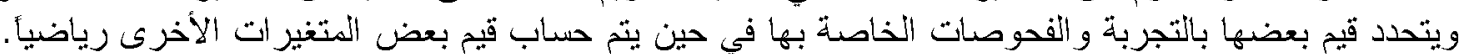

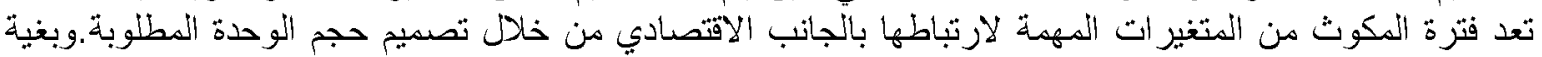

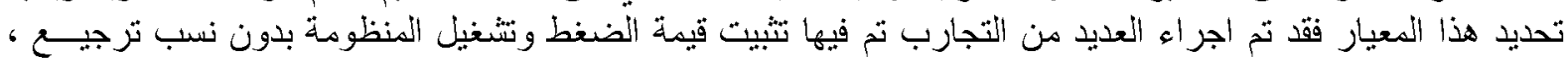

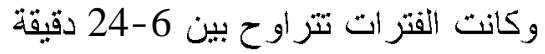

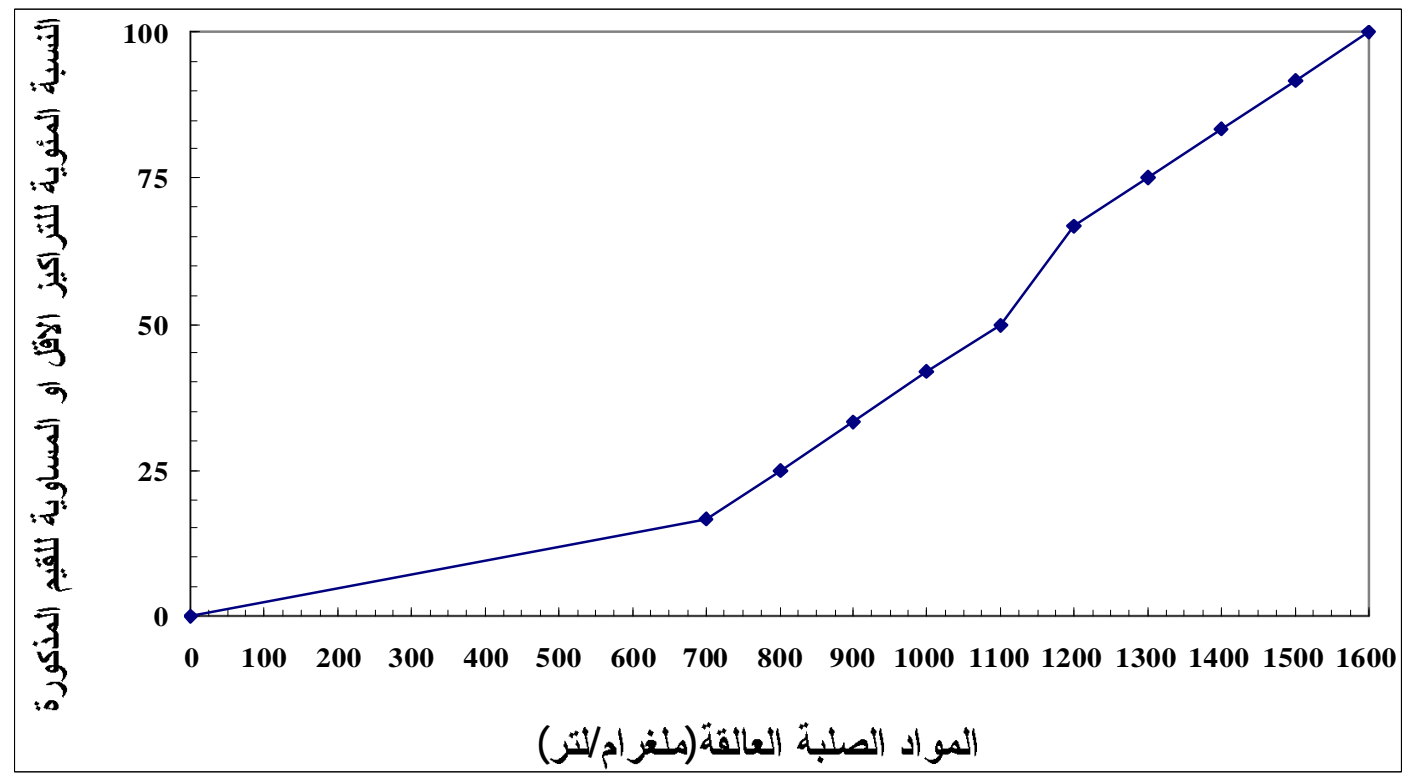

الثكل (2): التوزيع التكراري لتراكيز المواد الصلبة العالقة لمطروحات الالبان الحاوية على الثرش

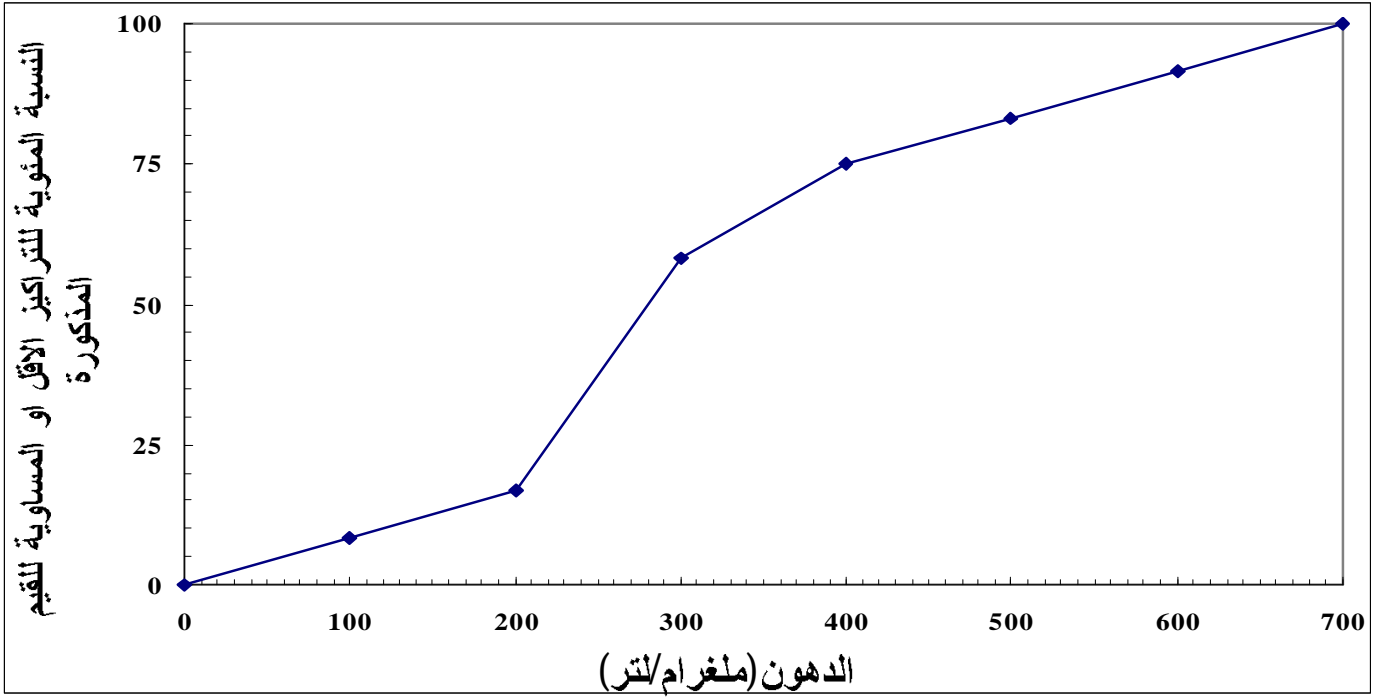

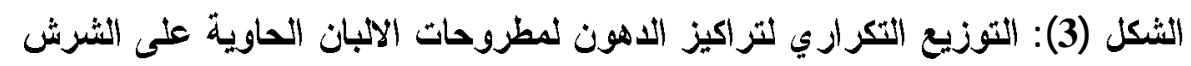

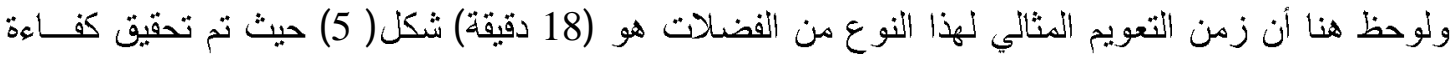

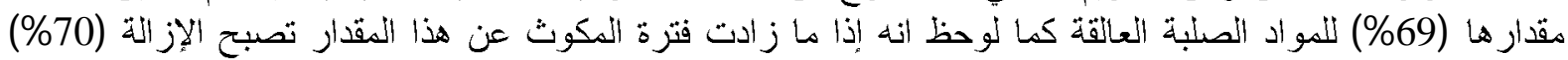

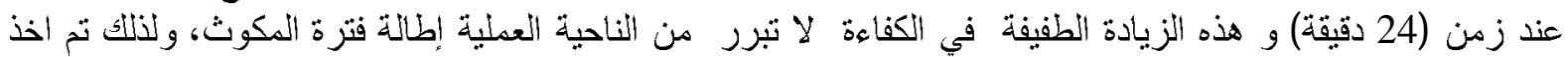

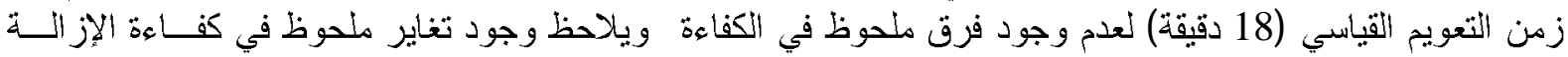




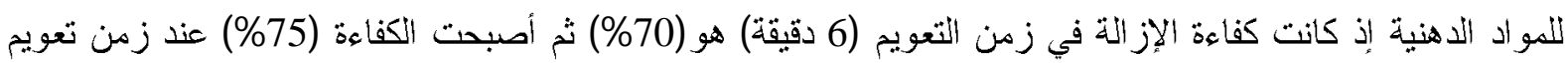

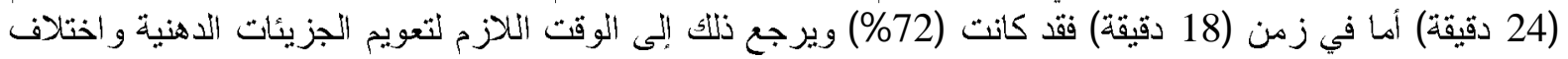

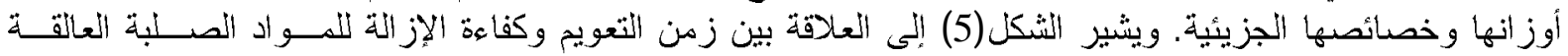

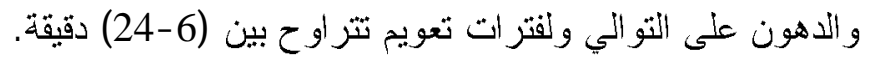

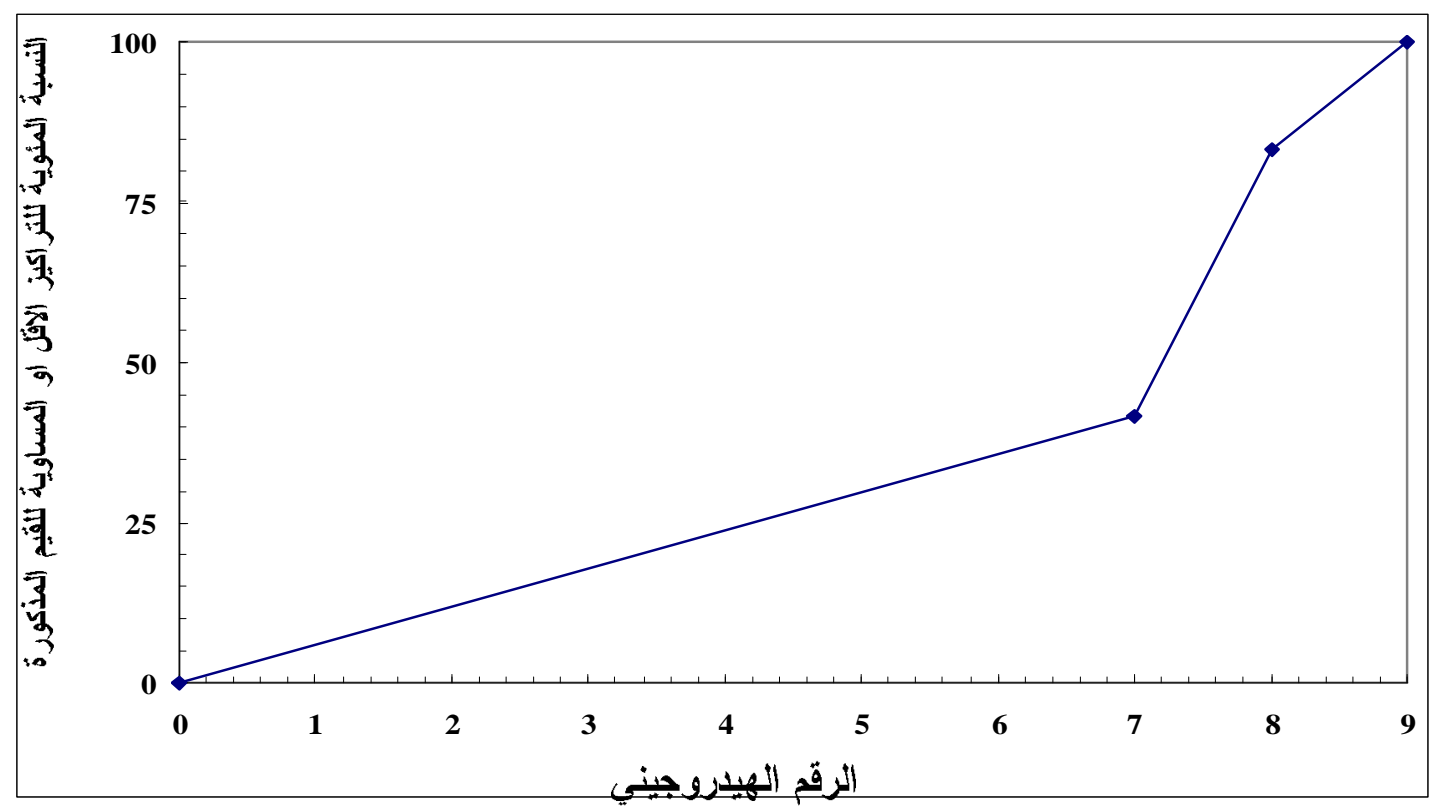

الثكل (4): التوزيع التكراري لقيم الرقم الهيدروجيني لمطروحات الالبان الحاوية على الثرش

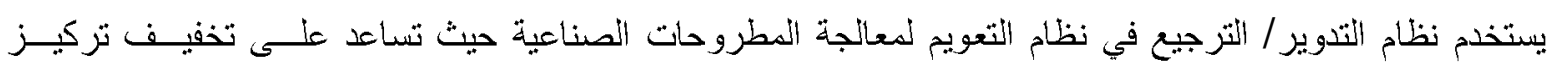

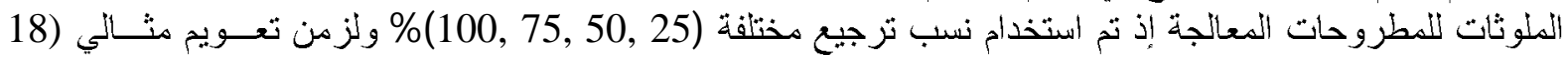

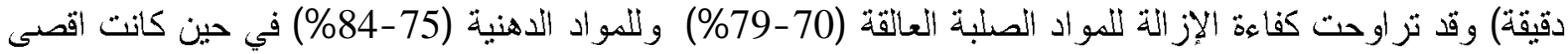

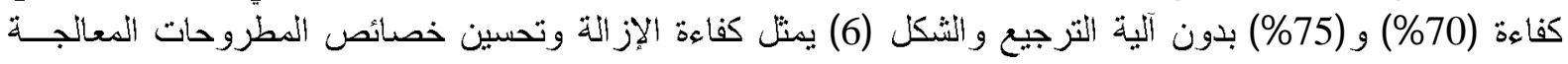
عند استخدام نسب تزجيع (20)

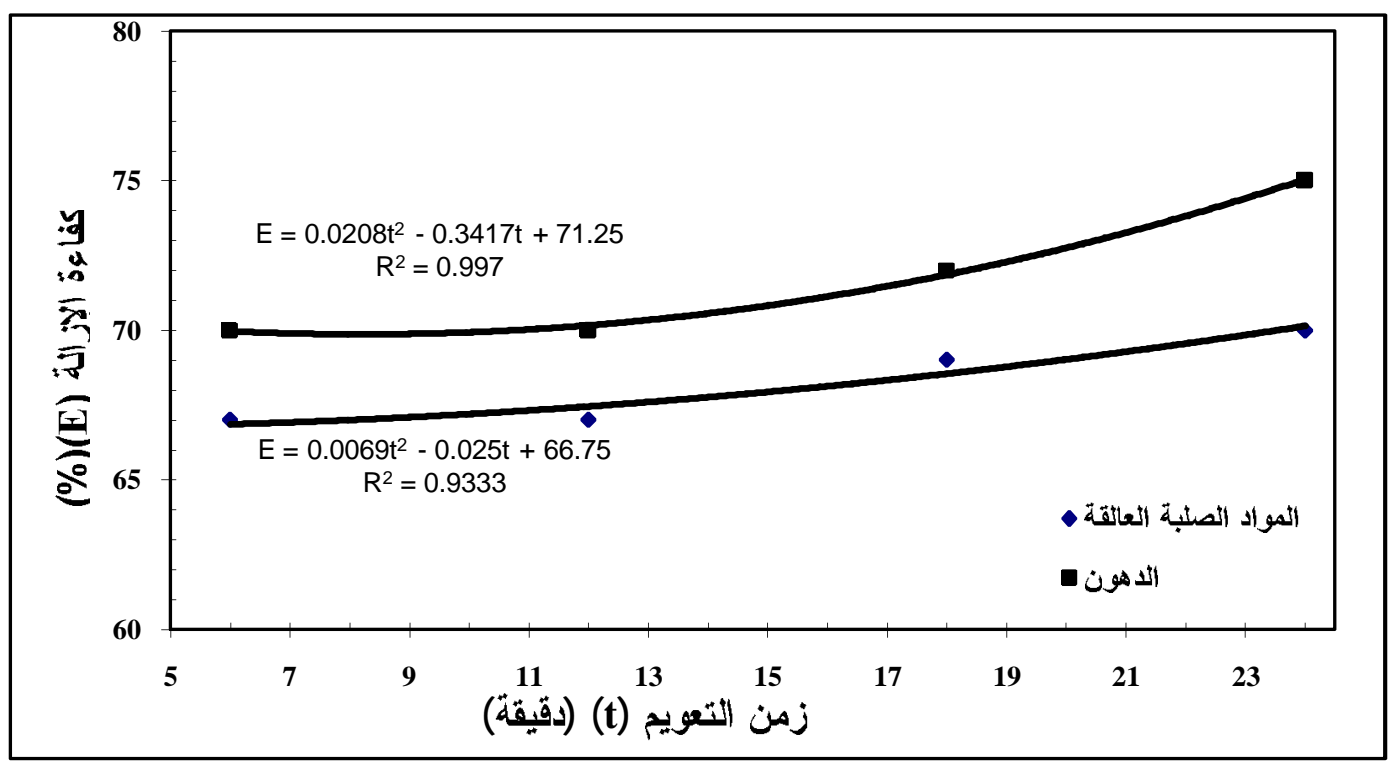

الثكل (5) : العلاقة بين زمن التعويم وكفاعة الإزالة لمطروحات الألبان الحاوية على الشرش 
$\begin{array}{llll}\text { Al-Rafidain Engineering } & \text { Vol.19 } & \text { No.1 } & \text { February } 2011\end{array}$

ولغرض إيجاد قيمة الضغط المناسب لإتمام عملية الاز الثة للملوثات فقد تم اعتماد زمن تعويم قياسي مقداره (18 ادقيقة)

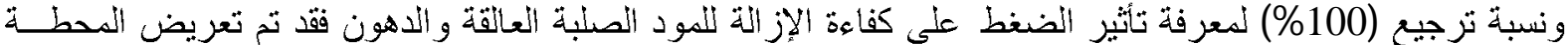

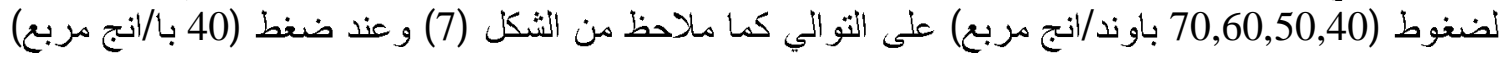

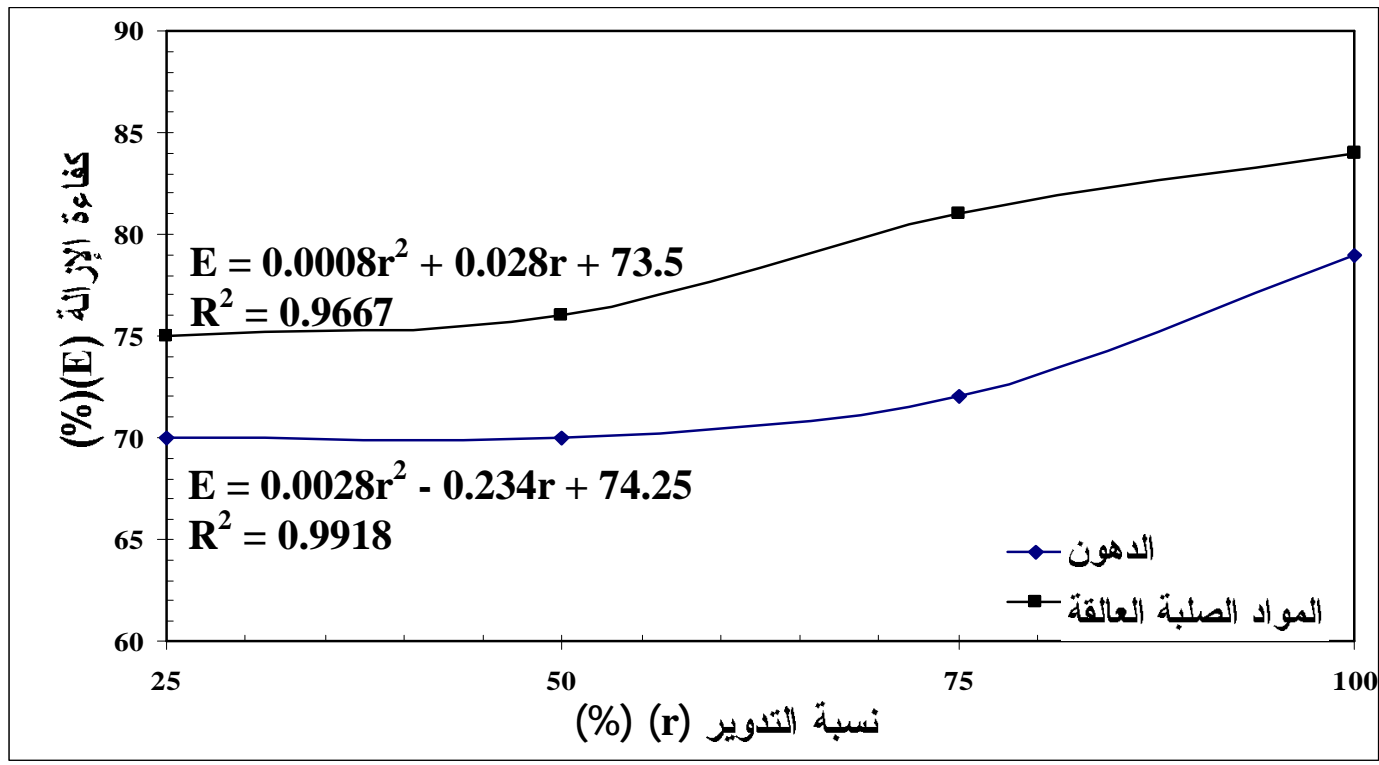

الثكل(6):العلاقة بين نسبة التدوير وكفاءة الاز التة لمطروحات الالبان الحاوية على الشرش

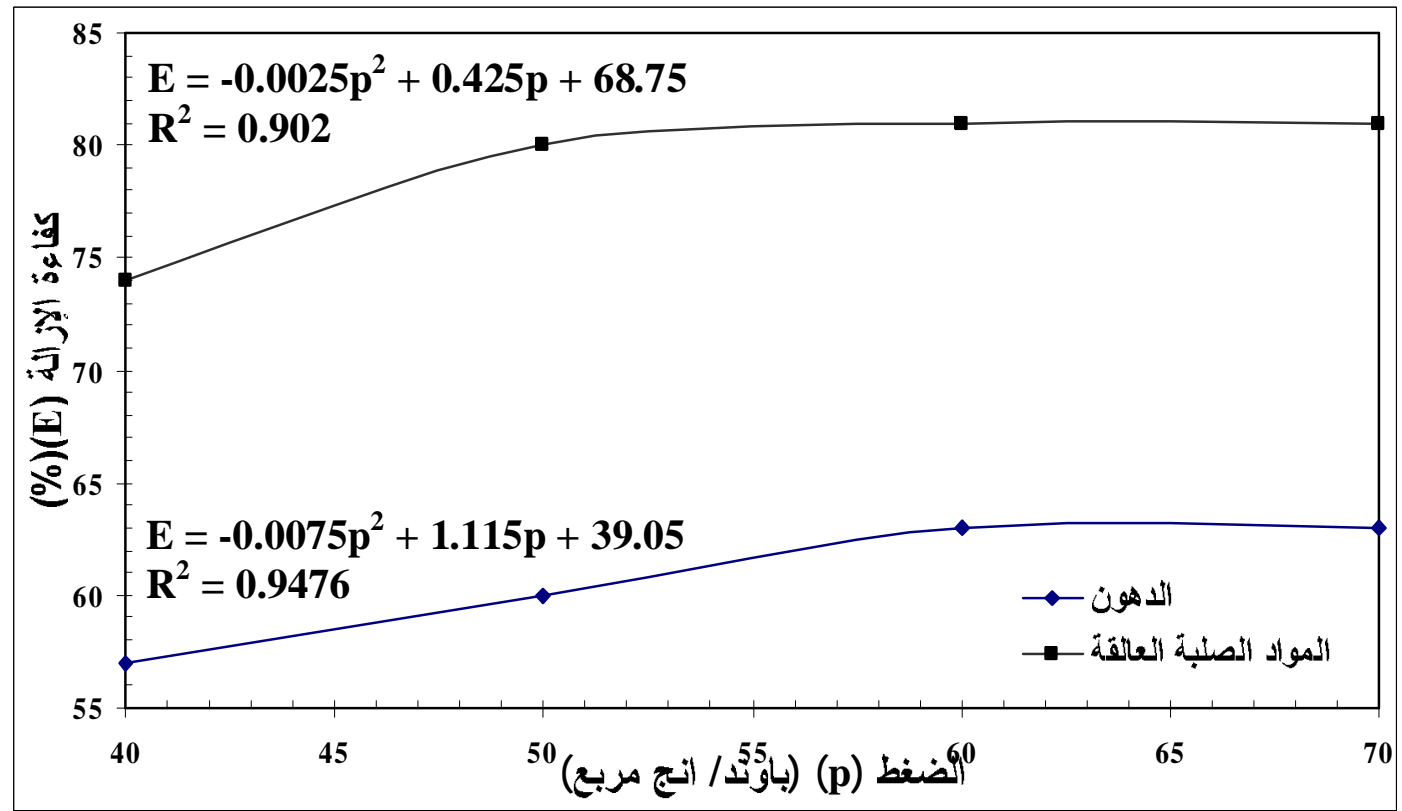

الثكل (7): العلاقة بين الضغط وكفاءة الاز الثة لمطروحات الالبان الحاوية على الثرش

كانت كفاءة إز الة المو اد العالقة (72 \% (82) و أصبحت عند ضغط (70با/انج مربع) (80\%) أما كفاءة إز الة الــدهون

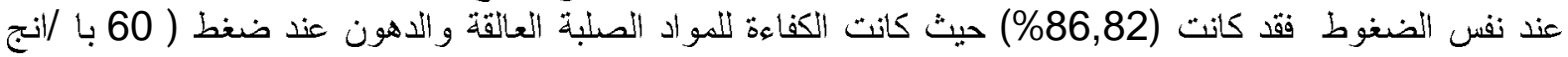

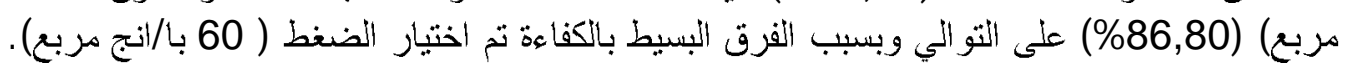

تأثير نسبة كمية الهواء إلى المواد الصلبة العالقة (A/S) على كفاءة الاز الثة

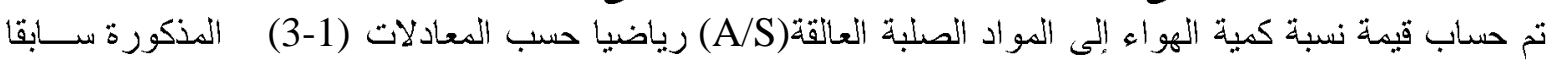

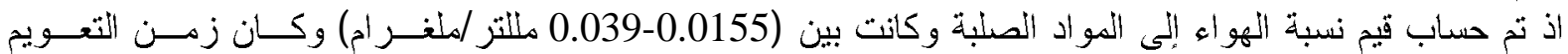




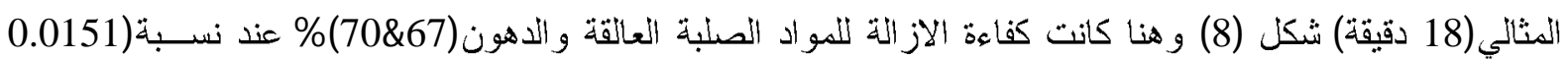

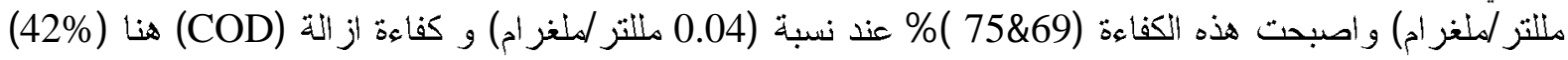
ويعود ذللك لاحتواء جزيئات الثرش على الثئ المواد الدهنية.

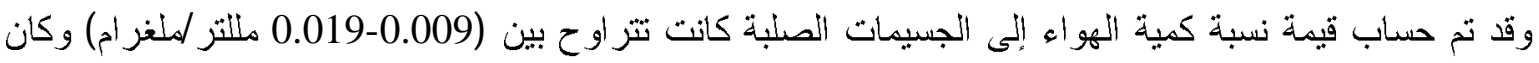

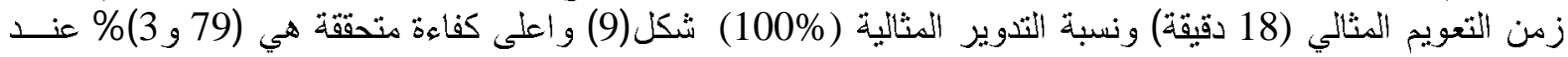

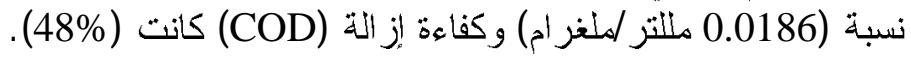

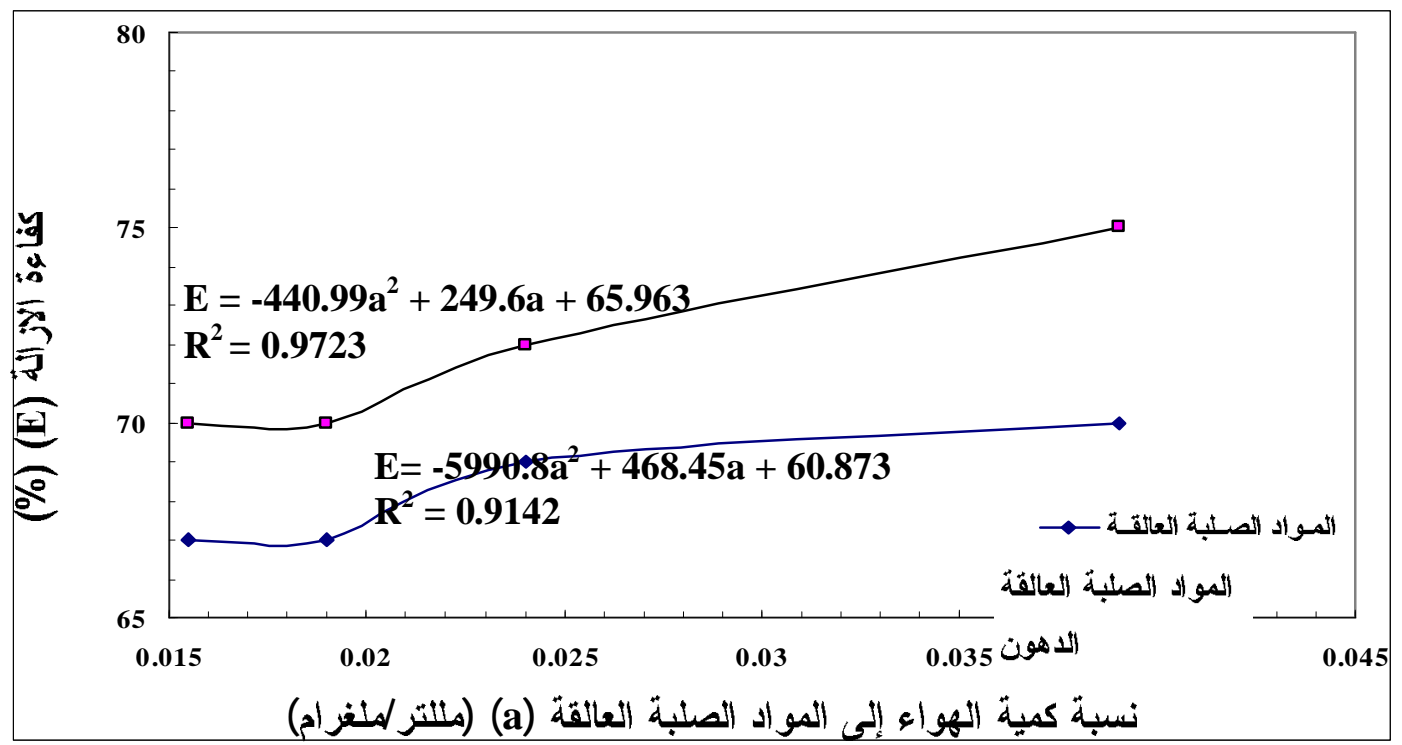

الثكل (8 ):العلاقة بين نسبة كمية الهواء إلى المواد الصلبة العالقة وكفاءة الإزالة لمطروحات معــل الألبـان

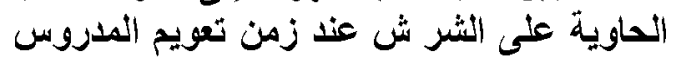

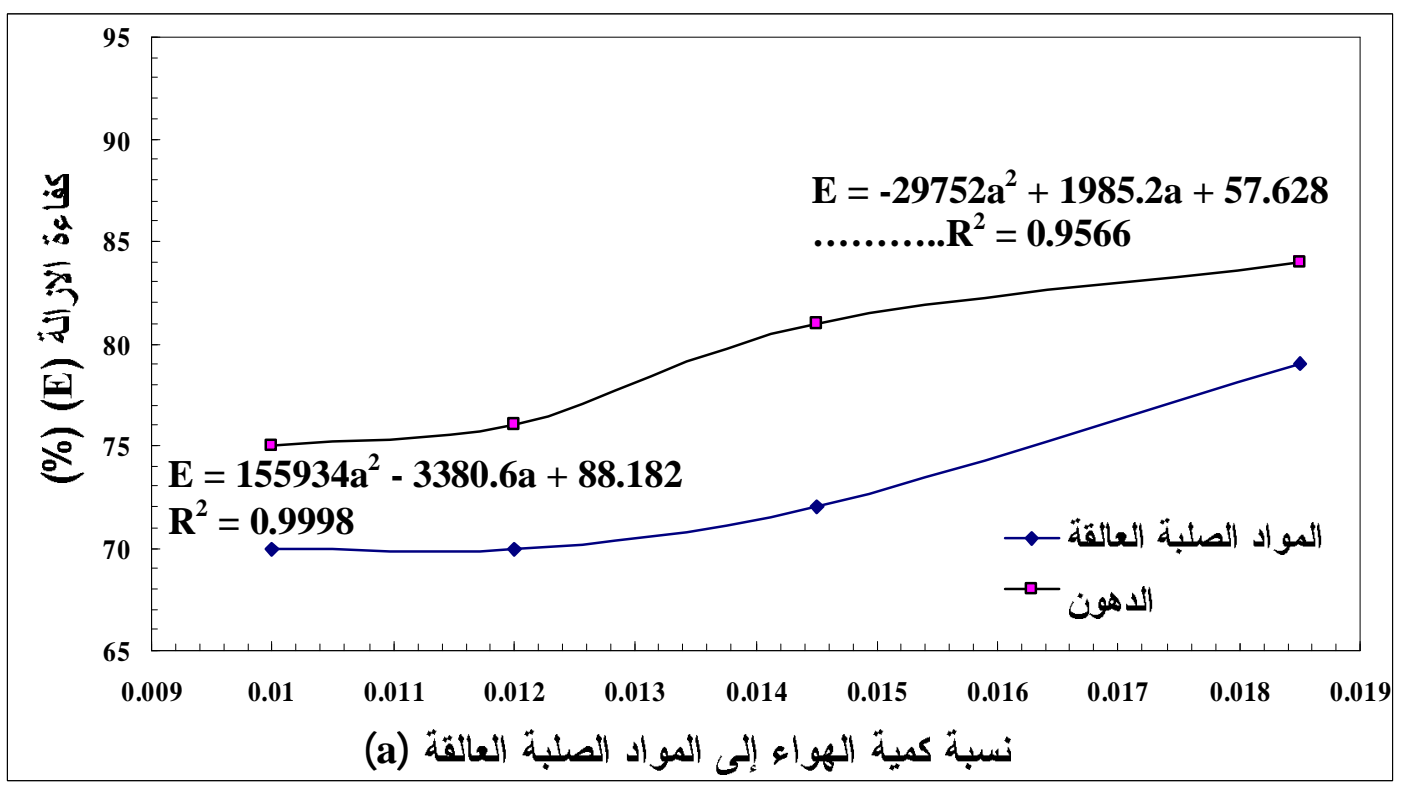

الثكل (9): العلاقة بين نسبة كمية الهواء إلى المواد الصلبة العالقة وكفاءة الإزالة لمطروحسات معــل الألبــان

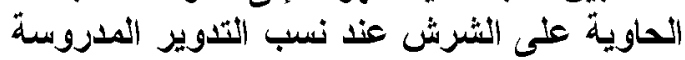

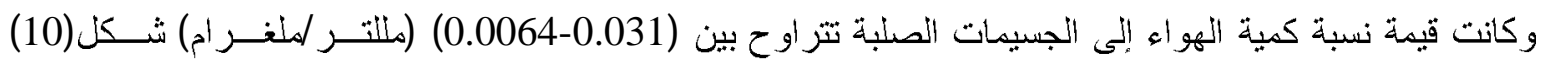

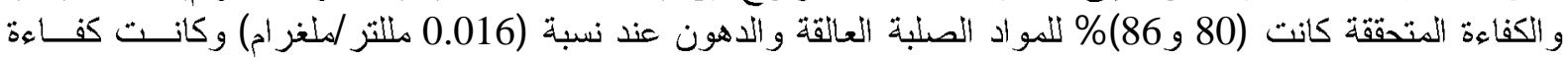

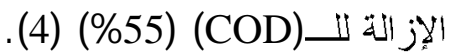




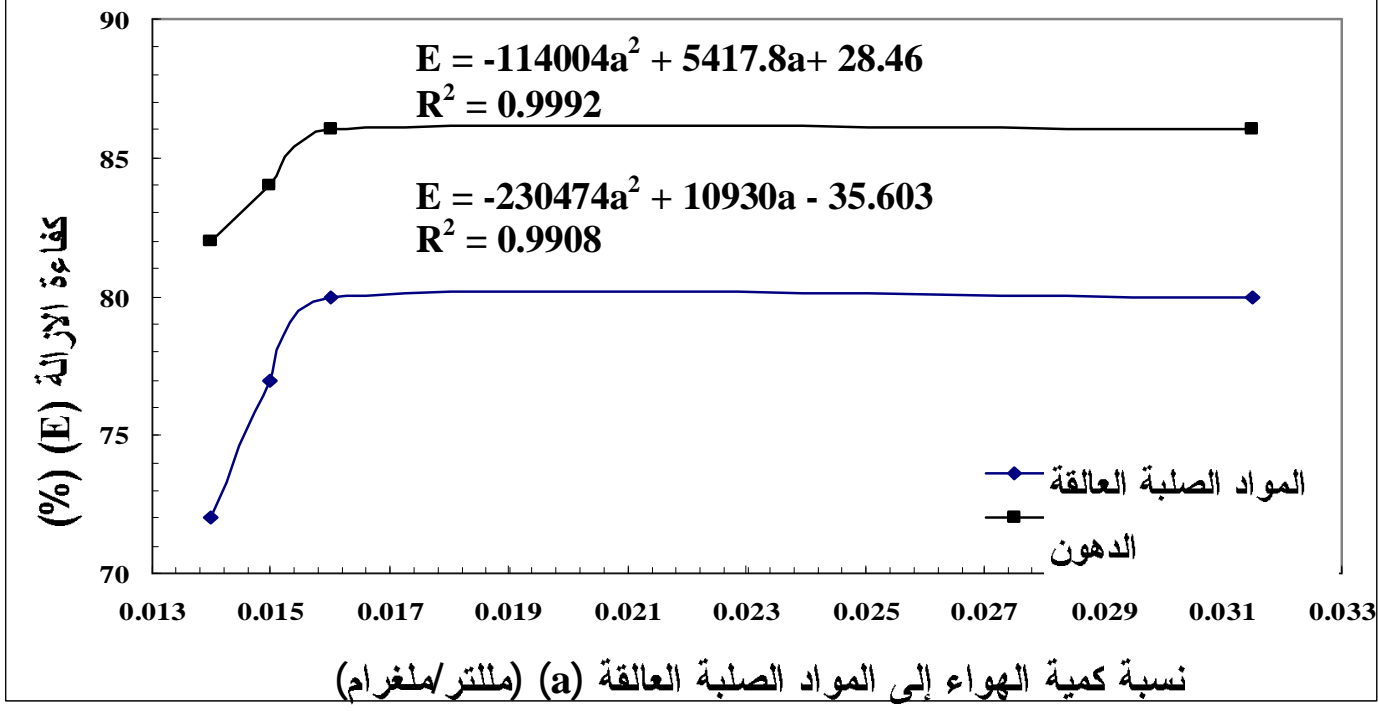

الثكل (10):العلاقة بين نسبة كمية الهواءو إلى المواد الصلبة العالقة وكفاءة المطروحات معمل الألبـان الحاويــة

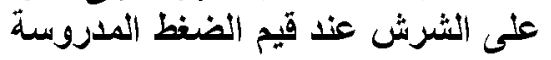

العلاقة بين المتغيرات المدروسة تم رسم العلاقة الموضحة بالثكلين (11) (12 ) بين كفاءة از التة المواد الصلبة العلالقة والـــهون خــلال الفتــرات الزمنية التي تم دراستها وهي (184،1246) دقيقة وتر اكيز المو اد الصنبة العالقة و الدهون ووجد انه لغرض تحقيـق

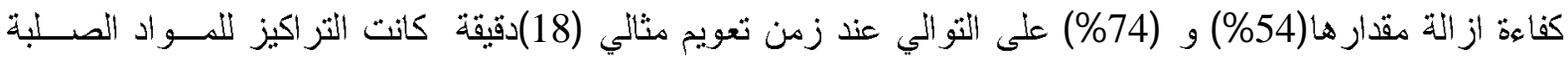

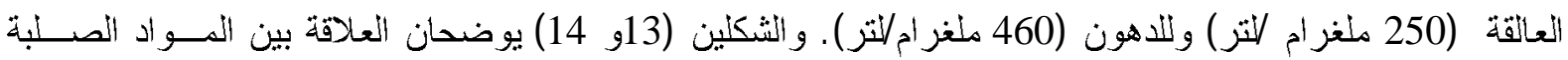

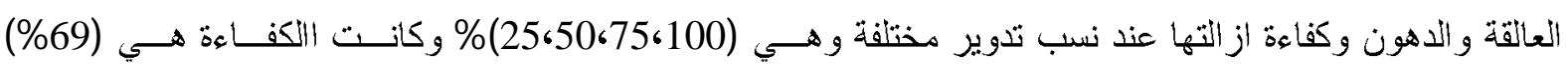

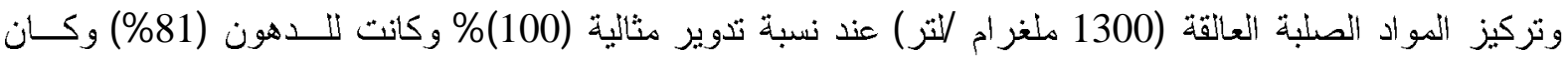
التركيز (525 ملغر ام لاتتز ). ولغرض توضيح العلاقة بين كفاءة الاز الة و المو اد الصلبة العالقة و الدهون الشكل (15)\&(16) عند ضـــط (40-

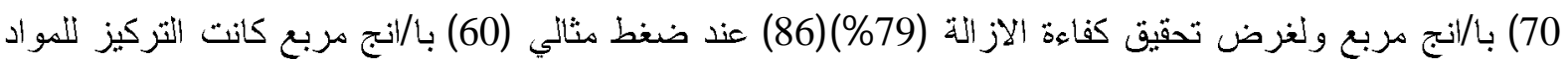

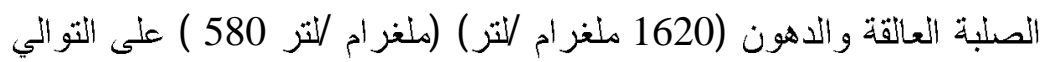

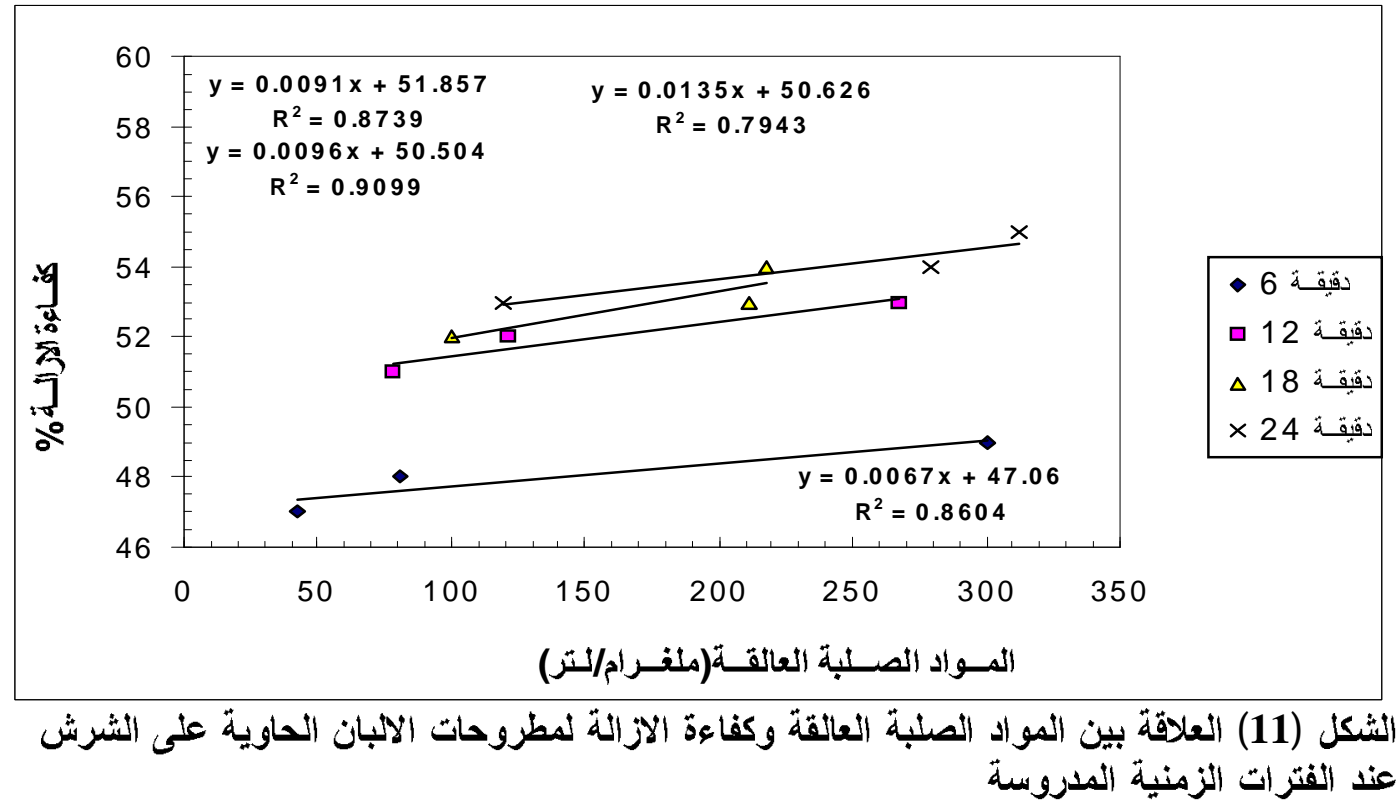


ألر اوي: إز الة الدهون و المو اد الصلبة العالقة من مطروحات صناعة الألبان الحاوية على الشرش باستخدام التعويم -

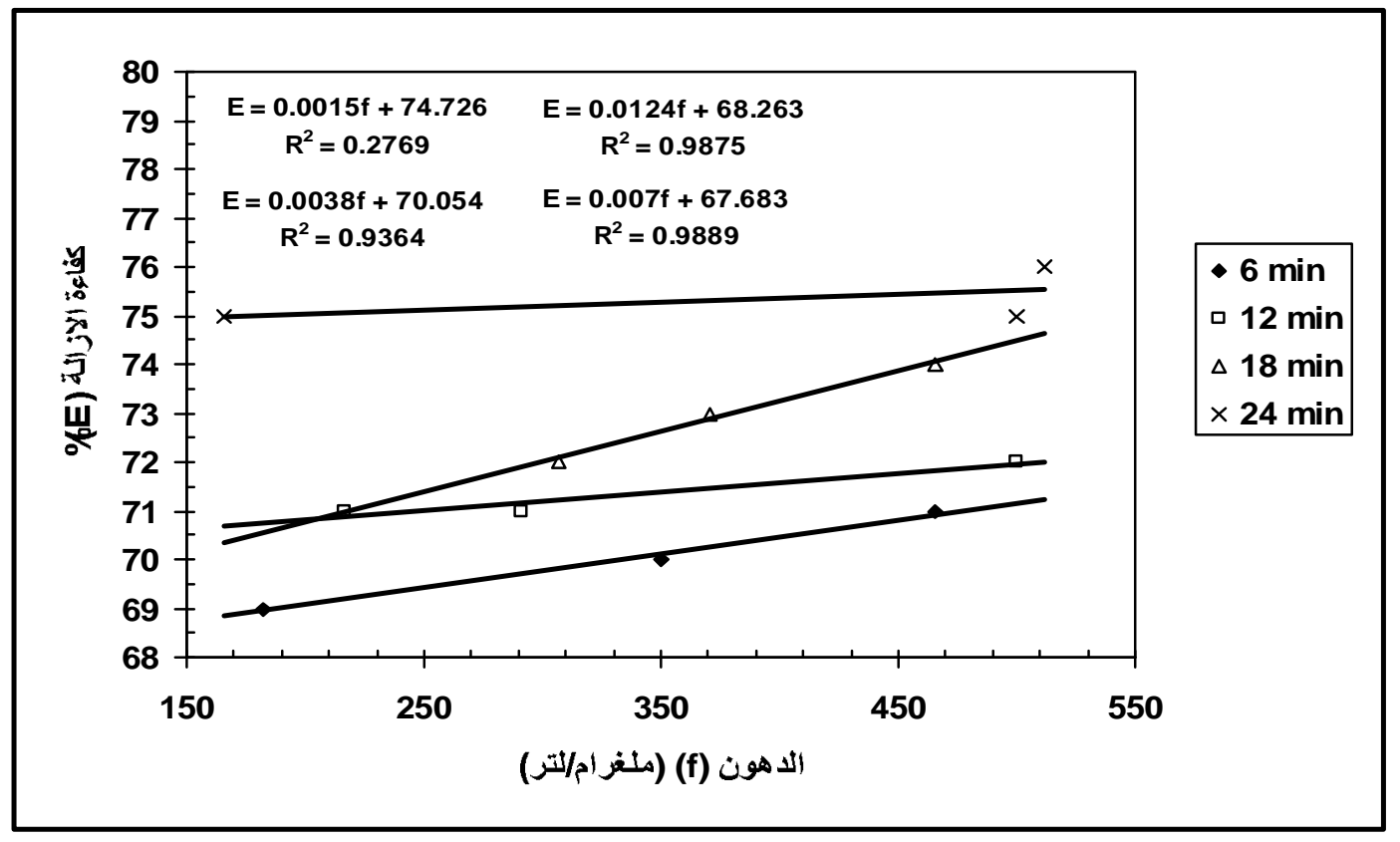

الثكل (12) العلاقة بين الاهون وكفاءة الاز الة لمطروحات الالبان الحاوية على الثرش عند

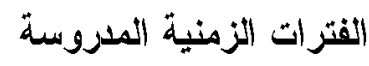

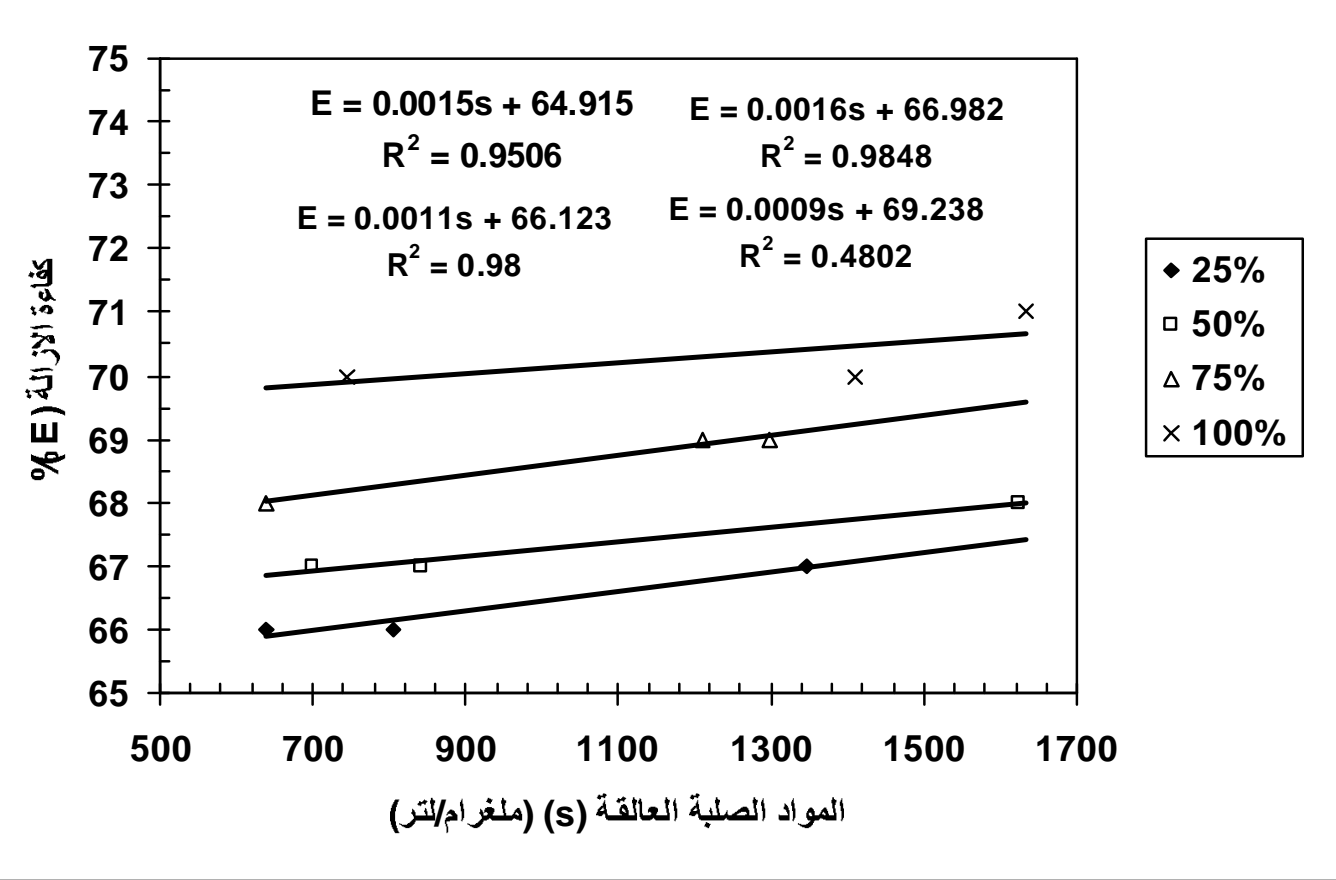

الثكل (13) العلاقة بين المواد الصلبة العالقة وكفاعة الازالة لمطروحات الألبان الحاوية الثرش عند

$$
\text { نسب التزرجيع المدروسة }
$$


Al-Rafidain Engineering

Vol.19

No.1

February 2011

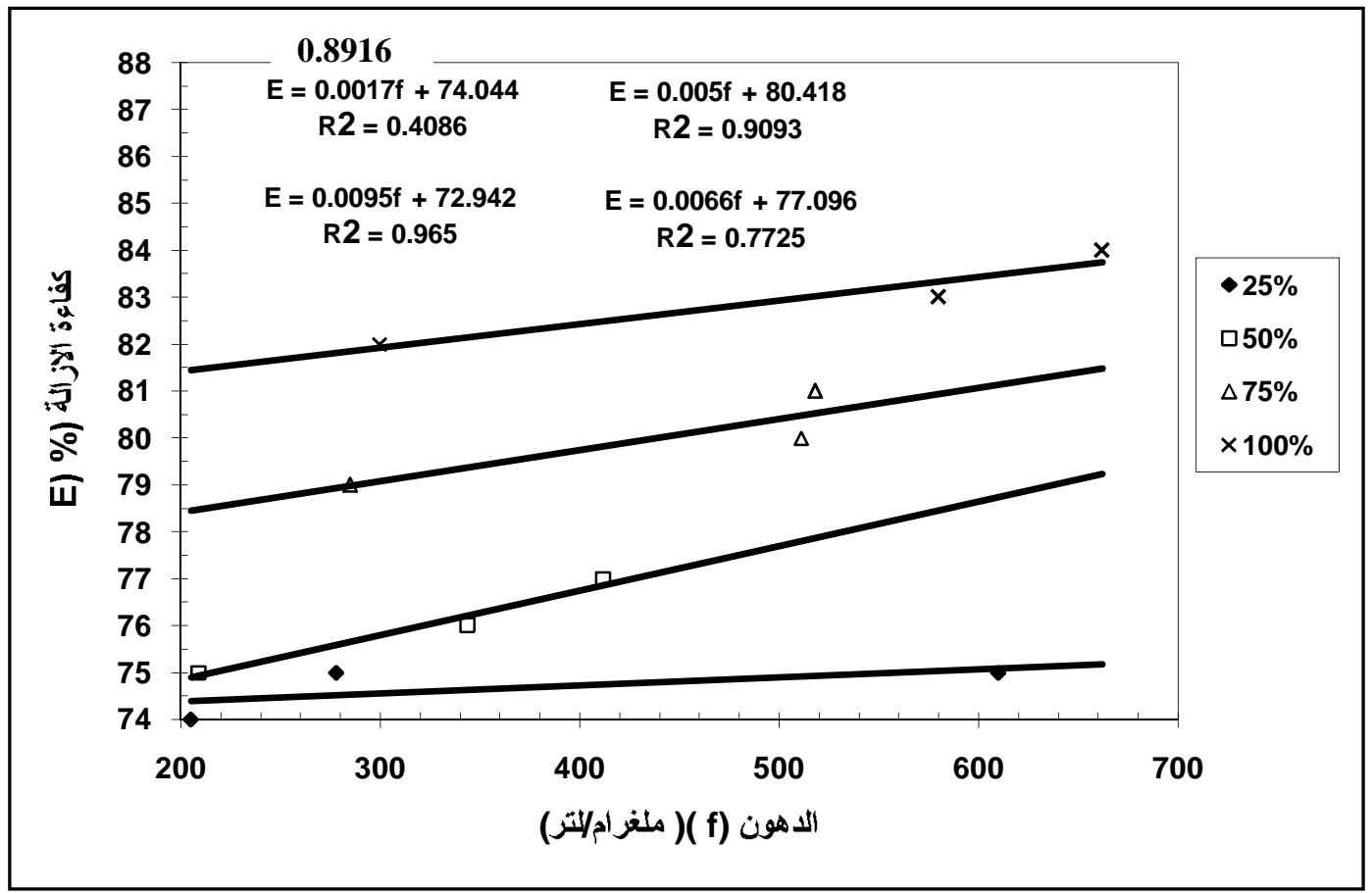

الثكل (14)العلاقة بين الدهون وكفاءة الازالة لمظروحات الألبان الحاوية على الثرش عند نسب الترجيع

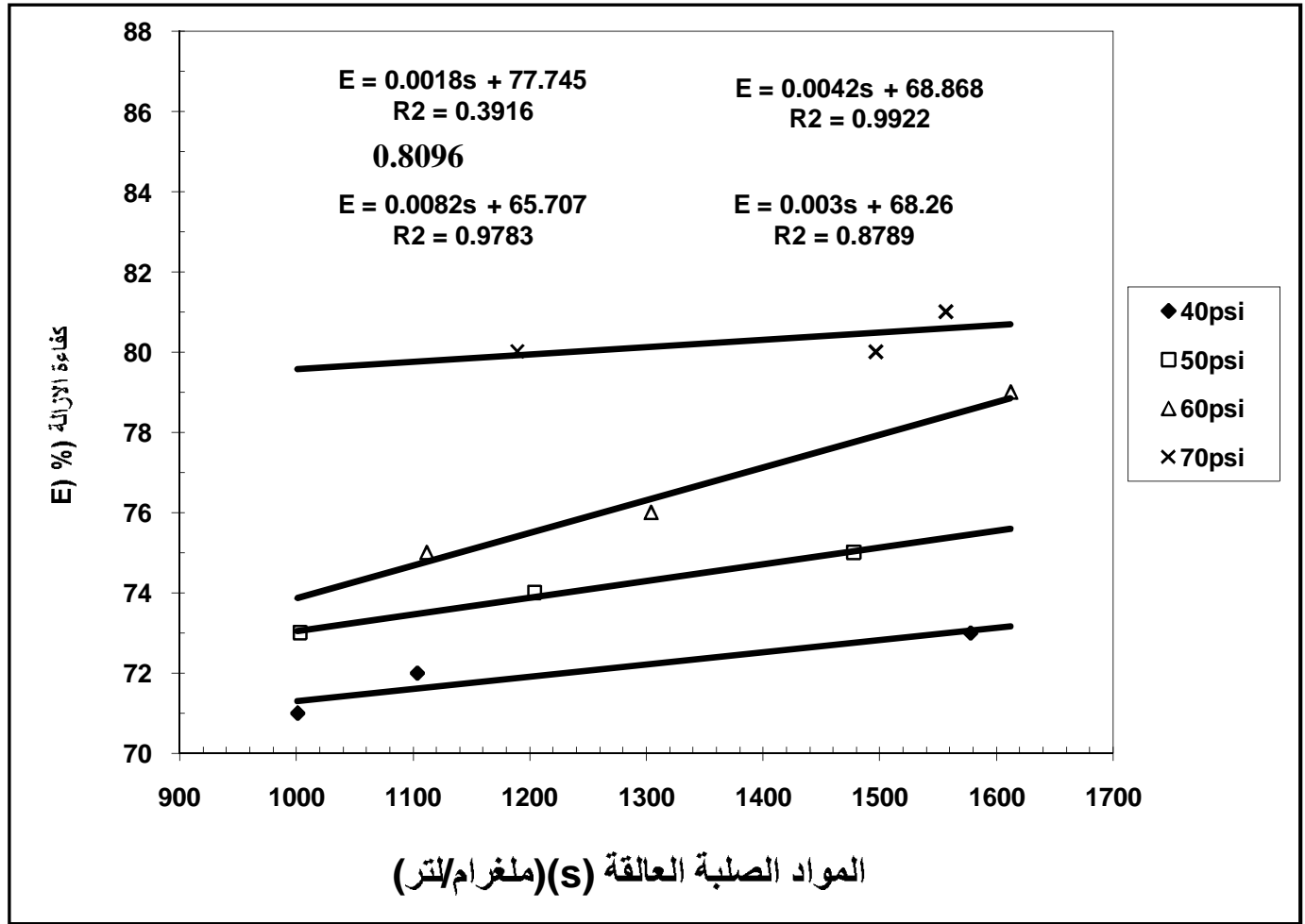

الثكل (15) العلاقة بين المواد الصلبة العالقة وكفاءة الازالة لنطروحات الالبان الحاوية على الشرش عند قيم الضغط المدروسة 


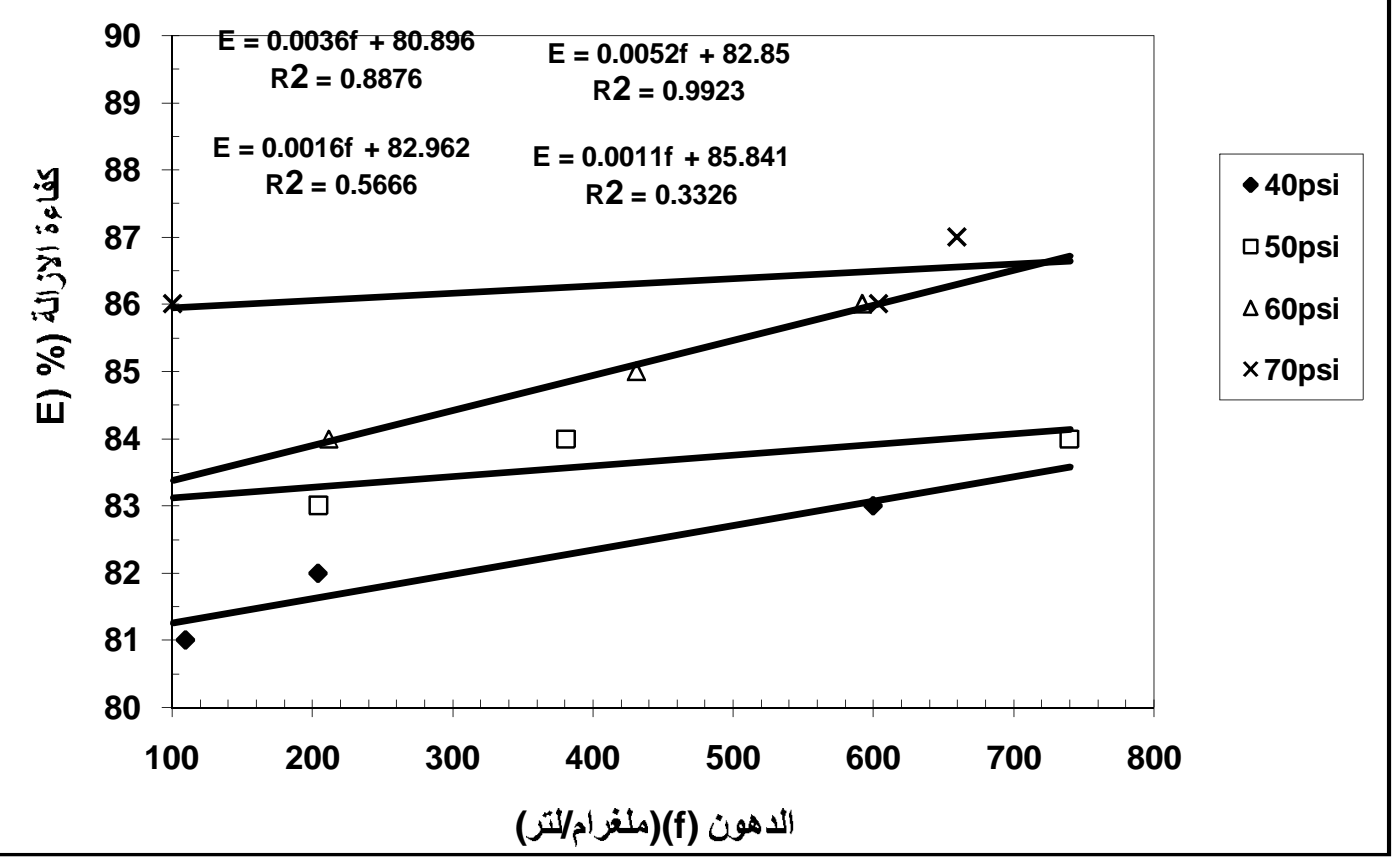

الثكل (16)العلاقة بين الدهون وكفاءة الاز الة لمطروحات الالبان الحاوية على الثرش عند قيم الضغط المدروسة

من خلال استعر اض ومناقتة النتائج التي تم الحصول عليها تم الخروج بالاستتناجات الآتية:

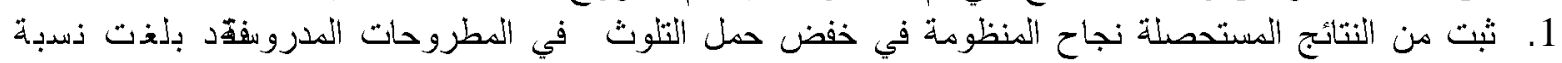

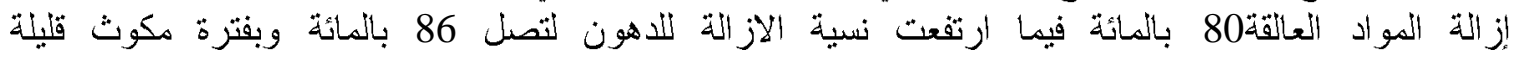

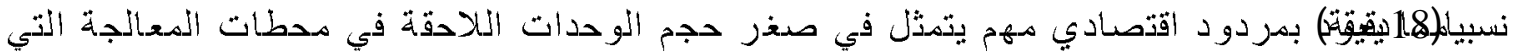
سوف نتبنى هذه المنظومة.

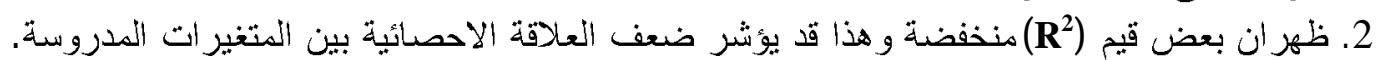

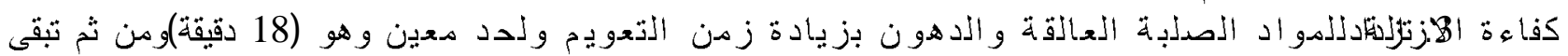

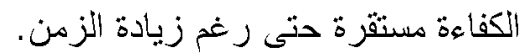

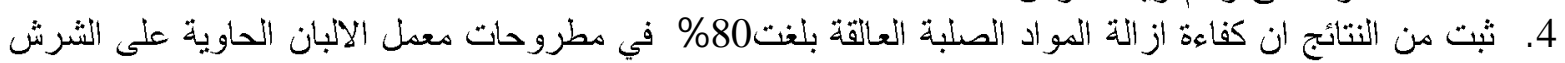

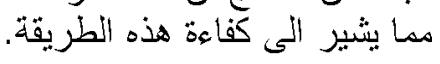
5. كانت كفاءة الإز التة للاهون في مطروحات معمل الالبان الحاوية على الثُش (86\%).

$$
\begin{aligned}
& \text { المصــــــادر } \\
& \text { 1. الر اوي ، ساطع ، " التلوث و التتمية الصناعية في الدول النامية"، اور اق مجمعية /المجمع } \\
& \text { العلمي العر اقي العدد 11 شباط (2002). }
\end{aligned}
$$

2.Puget, F.P. and Massarani,G. "Modeling of The Dispersed Air Flotation Process Applied to Dairy Wastewater Treatment "Brazilian journal of chemical Engineering, No.2, Vol.21 (2004).

3.Davies, K."DAF for Wastewater Treatment "Annual Water Industry and Operators Conference .Civil Centre -Shepparton, September (1998). 
4.Stephenson R.L. and Blackburn, J.B."Industrial Wastewater System" Handbook, Lewis publisher, USA(1998).

5.Jorgensen ,S.E. "Industrial Wastewater Management "Elsevier Scientific Publishing company, Amsterdam(1979).

6.Eckenfelder, W.W. "Industrial Water Pollution Control ", McGraw-Hill Book Company, New York (2000).

7.Metcalf and Eddy, Inc. "Wastewater Engineering Treatment $\&$ Reuse" $4^{\text {th }}$ edition, McGrawHill, Book Company: New York (2003).

8.Liu, D.H.F.and Liptak B.G."Wastewater Treatment "Lewis publisher, USA (2000).

9.APHA, AWWA, and WPCF" Standard Methods for the Examination of Water and Wastewater "20 $0^{\text {th }}$ ed. Public Health Assoc. Washington, D.C., USA (1998).

10.Brown, A.B.; Pico ,R.F. "Characterization and Treatment of Dairy Wastes in the Municipal Treatment System ",Proceeding of the $34^{\text {th }}$ Industrial Waste

11..Hendricks ,H. "Water treatment Unit Processes "Taylor \&Francis, USA, (2006).

تم اجراء البحث في كلية الهندسة - جامعة الموصل 